Article

\title{
Evaluation of Multi-Satellite Precipitation Products for Streamflow Simulations: A Case Study for the Han River Basin in the Korean Peninsula, East Asia
}

\author{
Thom Thi Vu, Li Li and Kyung Soo Jun * \\ Graduate School of Water Resources, Sungkyunkwan University, Suwon 16419, Korea; \\ vuthom.khtn@gmail.com (T.T.V.); lili0809@skku.edu (L.L.) \\ * Correspondence: ksjun@skku.edu; Tel.: +82-31-290-7515
}

Received: 27 March 2018; Accepted: 13 May 2018; Published: 16 May 2018

check for updates

\begin{abstract}
The accuracy and sufficiency of precipitation data play a key role in environmental research and hydrological models. They have a significant effect on the simulation results of hydrological models; therefore, reliable hydrological simulation in data-scarce areas is a challenging task. Advanced techniques can be utilized to improve the accuracy of satellite-derived rainfall data, which can be used to overcome the problem of data scarcity. Our study aims to (1) assess the accuracy of different satellite precipitation products such as Tropical Rainfall Measuring Mission (TRMM 3B42 V7), Precipitation Estimation from Remotely Sensed Information using Artificial Neural Networks (PERSIANN), PERSIANN-Climate Data Record (PERSIANN-CDR), and China Meteorological Assimilation Driving Datasets for the SWAT Model (CMADS) by comparing them with gauged rainfall data; and (2) apply them for runoff simulations for the Han River Basin in South Korea using the SWAT model. Based on the statistical measures, that is, the proportion correct (PC), the probability of detection (POD), the frequency bias index (FBI), the index of agreement (IOA), the root-mean-square-error (RMSE), the mean absolute error (MAE), the coefficient of determination $\left(\mathrm{R}^{2}\right)$, and the bias, the rainfall data of the TRMM and CMADS show a better accuracy than those of PERSIANN and PERSIANN-CDR when compared to rain gauge measurements. The TRMM and CMADS data capture the spatial rainfall patterns in mountainous areas as well. The streamflow simulated by the SWAT model using ground-based rainfall data agrees well with the observed streamflow with an average Nash-Sutcliffe efficiency (NSE) of 0.68 . The four satellite rainfall products were used as inputs in the SWAT model for streamflow simulation and the results were compared. The average $\mathrm{R}^{2}$, NSE, and percent bias (PBIAS) show that hydrological models using TRMM $\left(\mathrm{R}^{2}=0.54\right.$, $\mathrm{NSE}=0.49$, PBIAS $=[-52.70-28.30 \%])$ and CMADS $\left(\mathrm{R}^{2}=0.44, \mathrm{NSE}=0.42\right.$, PBIAS $\left.=[-29.30-41.80 \%]\right)$ data perform better than those utilizing PERSIANN $\left(\mathrm{R}^{2}=0.29, \mathrm{NSE}=0.13\right.$, PBIAS $\left.=[38.10-83.20 \%]\right)$ and PERSIANN-CDR $\left(\mathrm{R}^{2}=0.25, \mathrm{NSE}=0.16, \mathrm{PBIAS}=[12.70-71.20 \%]\right)$ data. Overall, the results of this study are satisfactory, given that rainfall data obtained from TRMM and CMADS can be used to simulate the streamflow of the Han River Basin with acceptable accuracy. Based on these results, TRMM and CMADS rainfall data play important roles in hydrological simulations and water resource management in the Han River Basin and in other regions with similar climate and topographical characteristics.
\end{abstract}

Keywords: TRMM; PERSIANN; PERSIANN-CDR; CMADS; satellite-derived rainfall; streamflow simulation; SWAT; Han River

\section{Introduction}

Precipitation is one of the most essential components of the hydrological cycle [1]. The quantity and quality of the precipitation data used as the principal input to hydrological models affect the 
accuracy of the simulation results [2,3]. Rain gauges provide direct precipitation measures; however, scarcity and irregularity problems with respect to the gauge network considerably influence the data reliability $[4,5]$. In addition, an effective spatial coverage of precipitation over a large area is difficult. Compared with rain gauges that provide rainfall data by accumulating rainfall over a time interval, weather radar systems provide an instantaneous spatial measure of precipitation and thus, produce rapid climate information [6]. However, Westrick et al. [7] investigated the limitations of the radar network for quantitative precipitation measurement and showed that the radar-derived precipitation estimates could not represent the regional precipitation since radar coverage is limited to lowland areas. The drawbacks of radar-derived data, such as coverage area limitations, costly infrastructure construction, and inaccuracy under complex atmospheric conditions, result in the poor performance of hydrological models [8]. Currently, visible and thermal infrared sensors onboard the geostationary Earth-orbiting satellites and passive microwave sensors onboard the low-Earth-orbiting satellites provide more accurate rainfall estimates at a higher measurement frequency. Based on the advancements of these techniques, several satellite-based precipitation products with global high-resolution (up to $0.25^{\circ}$ ) are now available such as those derived from the Tropical Rainfall Measuring Mission (TRMM), Precipitation Estimation from Remotely Sensed Information using Artificial Neural Networks (PERSIANN), and Climate Prediction Center morphing technique (CMORPH) [9]. Those global and near-real-time rainfall estimates are extremely attractive for hydrological and weather studies [10-12]. The rainfall estimates from PERSIANN, CMORPH, and TRMM-based Multi-satellite Precipitation Analysis (TMPA), which combines satellite data from different sensors and ground station data from the Global Precipitation Climatology Centre, have been widely applied in numerous studies [13-21]. Recently, the China Meteorological Assimilation Driving Datasets for the SWAT Model (CMADS), which consist of reanalyzed data based on assimilation techniques, provided important basic data (that is, rainfall, maximum and minimum temperature, solar radiation, relative humidity, and wind speed) that are extremely useful to analyze climate-water cycles and "macro" energy balances in hydrological studies [22,23]. The CMADS was developed by Dr. Xianyong Meng from the China Institute of Water Resources and Hydropower Research (IWHR) and has received worldwide attention [22]. Based on the full coverage of East Asia and an improved accuracy, CMADS promises to be one of the most useful satellite-derived weather datasets for meteorological and hydrological research.

Distributed hydrological models have been widely applied in water resource management and hydrological research [24]. They include the Hydrologic Simulation Program-Fortran (HSPF) [25], MIKE SHE [26], the Hydrologic Modeling System (HEC-HMS) [27], and the Soil and Water Assessment Tool (SWAT) [28]. Those models reduce the dependency on specific precipitation inputs and fully use satellite-based hydrometeorological data [29]. The SWAT has been widely applied because many studies showed that the SWAT model can simulate streamflow in regions with limited data well [30-32]. Studies of SWAT applications in South Korea include those by Kang et al. [33], Kim et al. [34], Bae et al. [35], Kim et al. [36], Shope et al. [37], and Cho et al. [38]. Kim et al. [34] suggested the integrated SWAT-MODFLOW model which can simulate the interaction between the river flow and the saturated aquifer. Kim et al. [36] proposed a method for the evaluation of the flow regulation effects by dams on river flow using the SWAT model for the Han River Basin. In those studies, the SWAT model was successfully applied to mountainous areas and river basins with various sizes; however, a SWAT model using satellite-based rainfall data has not been considered.

Satellite-derived rainfall estimates with high spatial resolution contribute to the water resources management especially in areas where the ground-based climate data are limited. The hydrologic performance of different satellite rainfall products varies regionally because of several factors such as instrument characteristics and retrieval algorithms. Kim et al. [39] compared four satellite precipitation products for the hydrological utility at a mountainous basin in South Korea and found that TMPAv6 and TMPAv7 products were closer to ground-based rainfall than CMORPH and global satellite mapping of 
precipitation (GSMaP). In the streamflow simulation, TMPAv6 and TMPAv7 performed well while CMORPH and GSMaP resulted in a large underestimation.

Although there are several flood control dams in the river, large floods have occurred in the downstream area of the Han River Basin, causing severe damages. The use of advanced techniques to predict precipitation that causes floods has attracted a large interest in recent years [40]. The application of satellite precipitation data with high accuracy and resolution has been widely studied to be able to respond quickly in real-world situations. Numerous studies successfully applied the SWAT model or used satellite rainfall products for various regions of South Korea. However, combining satellite rainfall products with the SWAT model was not considered. This study investigates the hydrologic application of different satellite rainfall products in the Han River Basin of South Korea by applying the SWAT model. The CMADS, a newly developed dataset with the full coverage of East Asia, was evaluated in comparison with other satellite rainfall products. This is a case study for a specific period from 2008 to 2013 as the CMADS is only available from 2008. This study aimed to (1) compare four satellite rainfall products (TRMM 3B42 V7, PERSIANN, PERSIANN-CDR, and CMADS) with gauge rainfall data; and (2) evaluate the accuracy and suitability of the four satellite precipitation products as inputs for streamflow simulations in the Han River Basin. The results of the study can provide information on the performance of different satellite rainfall products in hydrologic modeling for the Han River Basin. In addition, this study contributes to enriching the scientific database on hydrologic applications of different satellite precipitation datasets, especially for data scarce regions.

\section{Materials and Methods}

\subsection{Study Area}

This study focused on the Han River Basin; the river originates from Mt. Taebaek and flows into the Yellow Sea (Figure 1). The Han River Basin is the largest river basin $\left(26,219 \mathrm{~km}^{2}\right)$ in South Korea and occupies approximately $27 \%$ of the country's area [41]. The river has a total length of $5417 \mathrm{~km}$ and comprises of two major branches, that is, the North Han River (NHR; 10,652 $\mathrm{km}^{2}$ ) and South Han River (SHR; $12,514 \mathrm{~km}^{2}$ ). These branches converge at the immediate upstream of the Paldang Lake, which is the major source of water supply to the Seoul metropolitan area and forms the main stream (Figure 1).

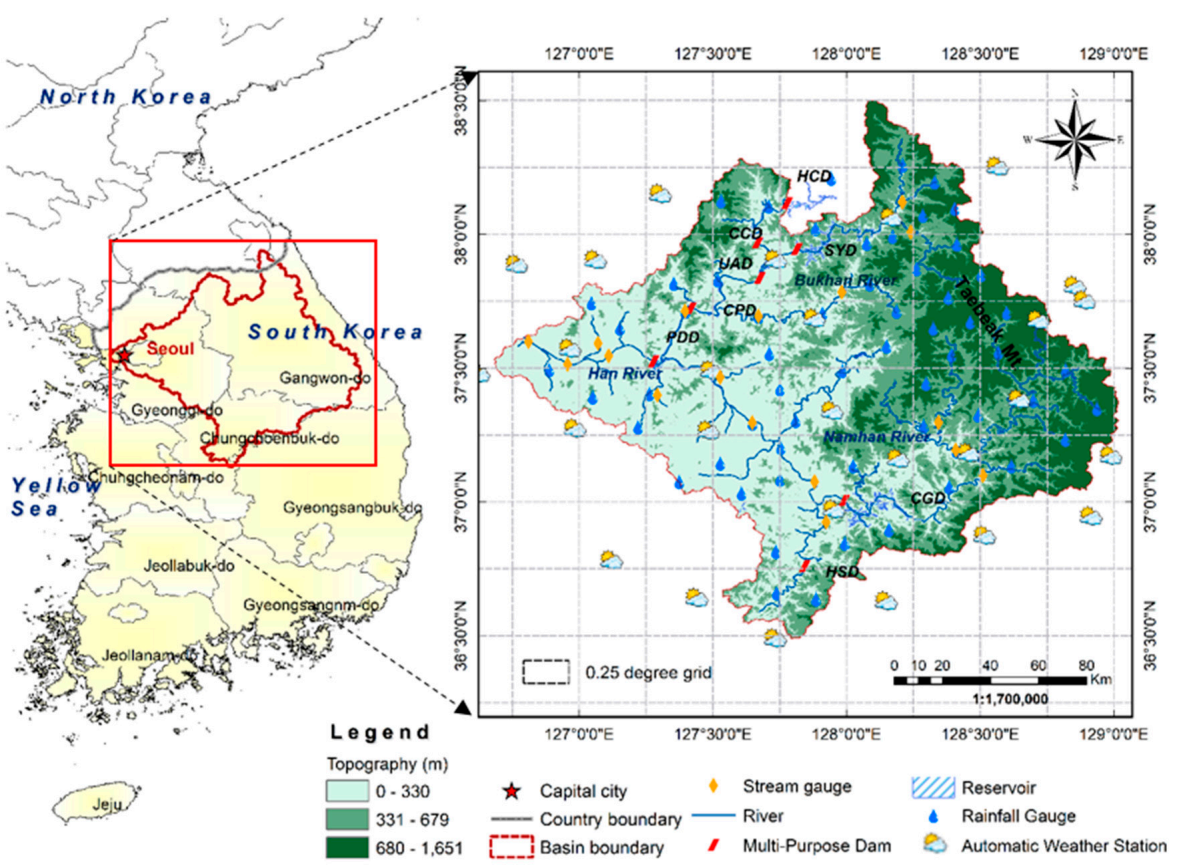

Figure 1. The Han River basin. 
The Han River Basin has four distinct seasons. The monthly average temperature varies from $-6{ }^{\circ} \mathrm{C}$ to $3{ }^{\circ} \mathrm{C}$ during winter and from $23{ }^{\circ} \mathrm{C}$ to $25{ }^{\circ} \mathrm{C}$ during summer. The average precipitation during the rainy season is $1272.5 \mathrm{~mm}$, which accounts for $70 \%$ of the average annual precipitation. A large amount of precipitation is concentrated in the mountainous area in the eastern part of the basin, while less precipitation occurs in the lowlands of the western part due to the influence of western North Pacific typhoons and summer monsoon precipitation [42,43].

Both precipitation and groundwater significantly affect the water resources of the Han River [44]. The surface runoff mainly originates from local precipitation during the summer monsoon season (June to September) and is maintained by groundwater seepage during the remainder of the year [44]. Several hydraulic structures, such as flood control dams, significantly affect the river flow (Figure 1). However, the flow of the Han River generally varies depending on the season, that is, it ranges from $150 \mathrm{~m}^{3} / \mathrm{s}$ in January to $4300 \mathrm{~m}^{3} / \mathrm{s}$ in August [44].

\subsection{Precipitation Data from Rain Gauges}

The ground-based precipitation data used in this study consist of daily records from 89 rain gauges from 2007 to 2013 (Figure 1). The daily precipitation data were gathered from an extensive ground-based data network consisting of 60 synoptic stations of the Water Management Information System and 29 automatic weather stations (AWS) of the Korea Meteorological Administration. At the AWS sites, rain is first detected by the sensor of the rain detector and then by the sensor of the tipping bucket rain gauge, with an accuracy of $0.5 \mathrm{~mm}$ [45]. Homogenization and outlier processing were used for the quality control of the gauged data [46].

In the Han River Basin, the precipitation data were collected from 89 gauge stations that could be considered as a large number of stations. For a precise climatological/hydrological study, however, 89 stations may not be sufficient for a basin with the area of $26,219 \mathrm{~km}^{2}$. Observations with more homogeneous distribution and fine spatial and temporal resolution could produce more accurate results. The limitation of ground-based observations can be compensated by well-validated satellite-derived estimates. Moreover, since various satellite-derived data are freely available, it could be a cost-effective way to collect data, especially for data-scarce areas.

\subsection{Satellite-Derived Precipitation Products}

\subsubsection{TRMM 3B42 Precipitation Products}

The TMPA generated precipitation data for a global coverage of $50^{\circ} \mathrm{N}-\mathrm{S}$ and spatial resolution of $0.25^{\circ} \times 0.25^{\circ}$ based on various meteorological satellites [47]. The TRMM 3B42 V7 includes two types of datasets, that is, the 3-hourly (corresponding to 3-hour intervals per day, that is, UTC 00:00, 03:00, 06:00, 09:00, 12:00, 15:00, 18:00, and 21:00) and the daily precipitation products. The datasets were obtained by the TRMM Algorithm 3B42, which was calibrated by multiple independent precipitation estimates from the optimal combination of 2B-31, 2A-12, Special Sensor Microwave Imager, Special Sensor Microwave Imager/Sounder, Advanced Microwave Sounding Unit, Microwave Humidity Sounder, and microwave-adjusted merged geo-infrared (IR). In this study, TRMM 3B42 V7 satellite rainfall data with a daily resolution were used for the period of 2008-2013. The data can be downloaded from the Goddard Space Flight Center website (https:/ / mirador.gsfc.nasa.gov).

\subsubsection{PERSIANN and PERSIANN-CDR Products}

The PERSIANN data were produced by using the artificial neural network algorithm to estimate the rainfall rate based on longwave IR images from geostationary Earth-orbiting satellites. Rainfall data with a spatial coverage of $60^{\circ} \mathrm{S}-\mathrm{N}$ and spatial resolution of $0.25^{\circ} \times 0.25^{\circ}$ are available for March 2000 to the present [48]. The PERSIANN-CDR rainfall data were generated by the PERSIANN algorithm using Gridsat-B1 IR satellite data and the bias was adjusted using monthly products from the Global Precipitation Climatology Project. The spatial resolution and coverage of this rainfall product are 
consistent with that of the PERSIANN dataset; data are available for January 1983 to April 2017. In this study, both the PERSIANN and PERSIANN-CDR products on a daily time scale were obtained from the Center for Hydrometeorology and Remote Sensing (http://chrsdata.eng.uci.edu/) from 2008 to 2013.

\subsubsection{CMADS Precipitation Products}

The CMADS is an atmospheric reanalysis dataset, which is obtained by using various assimilation techniques and multi-source data. The Space and Time Multiscale Analysis System (STMAS) assimilation technique combined with big data projection and processing methods was used to produce the CMADS climate dataset. Multi-source data were obtained from the National Centers for Environmental Prediction/National Center for the Atmospheric Research NCEP/NCAR-R1 reanalysis dataset, the National Centers for Environmental Prediction-Department of Energy (NCEP-DOE)-(R2) reanalysis dataset, the Climate Forecast System Reanalysis (CFSR) by NCEP, the European Centre for Medium-Range Weather Forecasts 15-year Reanalysis (ECMWF ERA-15), the ECMWF Reanalysis (ERA-40), the ECMWF Reanalysis-Interim (ERA-Interim), the Japanese 25-year Reanalysis project (JRA-25), and the CMA Land Data Assimilation System (CLDAS) [22]. The CMADS rainfall data provided by the China National Meteorological Information Center were produced using CMORPH's integrated precipitation products and validated with gauged rainfall data. In this study, CMADS V1.1 data (2008-2013) with a spatial coverage of $60^{\circ} \mathrm{E}-160^{\circ} \mathrm{E}$ longitude and $0^{\circ} \mathrm{N}-65^{\circ} \mathrm{N}$ latitude, daily resolution, and spatial resolution of $0.25^{\circ} \times 0.25^{\circ}$ were used. The detailed description of different satellite rainfall datasets is shown in Table 1.

Table 1. The description of satellite-based rainfall datasets used in this study.

\begin{tabular}{cccccc}
\hline Dataset & Version & Spatial/Temporal Resolution & Areal Coverage & Time Coverage & Sources \\
\hline TRMM & $3 \mathrm{~B} 42 \mathrm{V7}$ & $0.250 /$ daily & Near Global & 1998-present & Huffman et al. [47] \\
PERSIANN & - & $0.250 /$ daily & Near Global & 2000-present & Sorooshian et al. [48] \\
PERSIANN-CDR & CDR & $0.250 /$ daily & Near Global & $1983-2017$ & Ashouri et al. [49] \\
CMADS & V1.1 & $0.250 /$ daily & East Asia & 2008-2014 & Meng [22] \\
\hline
\end{tabular}

\subsection{SWAT Model}

The SWAT is a conceptual and semi-distributed model that simulates, based on a daily time step, various variables related to hydrology, weather, soil erosion, soil temperature, plant growth, nutrients, pesticides, and land management [28]. The SWAT model uses the SCS curve number and modified rational methods to calculate the surface runoff and estimate the peak discharge, respectively. The Penman-Monteith and Muskingum methods are used to simulate the evapotranspiration and channel routing, respectively [50]. Based on a delineation process, the basin is divided into sub-basins and hydrologic response units utilizing three essential inputs including the digital elevation model, land use map, and soil map.

Daily rainfall data from 89 stations and other climate data including air temperature, relative humidity, wind speed, and solar radiation from 29 meteorology stations were used as inputs to the model. The outflow of eight reservoirs (Figure 1) obtained from the Korea Water Resources Management Information System were also used as model input. A detailed description of the input data for the SWAT model is shown in Table 2. The SWAT-CUP sequential uncertainty fitting (SUFI-2) program was used for the autocalibration and sensitivity analysis of the SWAT model [51]. In the SUFI-2 program, the calibration objective was to maximize the NSE [52,53]. The SUFI-2 algorithm has been widely used for the calibration of the SWAT model. Wu and Chen [54] and Khoi et al. [55] showed that the SWAT model calibrated with the SUFI-2 algorithm makes better and reasonable predictions than models calibrated with other auto-calibrated methods. To construct a homogeneous set of optimal parameters for the model, a calibration was performed using the streamflow (2008-2010) measured at 16 gauging stations in the main branches. The calibrated parameters were then used for the model validation (2011-2013). The data from 2007 were used for the model warm-up. 
Table 2. The description of the input data used in the Soil and Water Assessment Tool (SWAT).

\begin{tabular}{cccc}
\hline Data Type & Data Description & Scale & Data Source \\
\hline Topography map & Digital elevation map (DEM) & $90 \mathrm{~m}$ & USGS-HydroSHEDS \\
\hline Land-use/Land cover map & Land use/Land cover classification 2010 & $1: 1,250,000$ & Korea Ministry of Environment \\
\hline Soil map & Soil types (2007) & Food and Agriculture Organization \\
\hline Meteorology & $\begin{array}{c}\text { Daily precipitation, Minimum and } \\
\text { Relative humidity, Wind speed }\end{array}$ & $1990-2013$ & $\begin{array}{c}\text { Korea Meteorological Administration } \\
\text { and Water Resources Management } \\
\text { Information System }\end{array}$ \\
\hline Hydrological data & $\begin{array}{c}\text { Discharge, Dam operation, } \\
\text { Reservoir characteristics }\end{array}$ & 2008-2013 & $\begin{array}{c}\text { Water Resources Management } \\
\text { Information System }\end{array}$ \\
\hline
\end{tabular}

\subsection{Statistical Measures for Precipitation and Runoff}

The spatiotemporal variability of satellite precipitation products was compared to the ground-based data by pixel-to-point comparison. To categorically evaluate and compare the daily satellite-derived precipitation data with ground-based precipitation data, three statistical measures were calculated, including the proportion correct (PC), probability of detection (POD), and frequency bias index (FBI) [56,57]. Those statistical measures indicate the detection capability of satellite rainfall data to estimate the possibility of precipitation events. A precipitation event represents a precipitation day when the daily rainfall is greater than $1 \mathrm{~mm}$ /day. The POD, PC, and FBI are defined as follows:

$$
\begin{gathered}
\mathrm{PC}=(a+d) / n \\
\mathrm{POD}=a /(a+c) \\
\mathrm{FBI}=(a+b) /(a+c),
\end{gathered}
$$

where $a, b, c$, and $d$ are the numbers of precipitation events ( $a$ : satellite yes, observation yes; $b$ : satellite yes, observation no; $c$ : satellite no, observation yes; and $d$ : satellite no, observation no) and $n$ is the total number of satellite observation pairs.

The POD, which is also called the hit rate, determines the likelihood of detected rainfall data and the PC represents the accuracy of detected rainfall data. The POD and PC values range from 0 to 1 and can be used to assess the level of agreement between satellite-based rainfall and the gauged values. The perfect POD and PC score is 1 . The FBI ranges from 0 to infinity, with a perfect score of 1 . These three statistical indicators were calculated using a $2 \times 2$ contingency table (Table 3 ).

Table 3. The contingency table for the satellite and gauged precipitations with a threshold of $1.0 \mathrm{~mm}$.

\begin{tabular}{cccc}
\hline \multirow{2}{*}{ Satellite Event } & \multicolumn{2}{c}{ Observation Event } & \multirow{2}{*}{ Marginal Total } \\
\cline { 2 - 3 } & Yes $(\boldsymbol{p} \geq \mathbf{1 . 0} \mathbf{~ m m})$ & No $(p<\mathbf{1 . 0} \mathbf{~ m m})$ & \\
\hline Yes $(p \geq 1.0 \mathrm{~mm})$ & $a$ & $b$ & $a+b$ \\
No $(p<1.0 \mathrm{~mm})$ & $c$ & $d$ & $c+d$ \\
Marginal total & $a+c$ & $b+d$ & $n=a+b+c+d$ \\
\hline
\end{tabular}

To evaluate the accuracy of satellite-derived rainfall data by comparing them with gauged precipitation, five statistical indicators were adopted, including the index of agreement (IOA), the root-mean-square-error (RMSE), the mean absolute error (MAE), the coefficient of determination $\left(\mathrm{R}^{2}\right)$, and the bias [57]. The IOA measures additive and proportional differences in the observed and satellite-derived means and variances. The RMSE measures the average magnitude of the errors. Since the errors are squared before averaged, RMSE gives relatively high weights to large errors. The MAE is a linear score which means that all the individual differences are weighted equally in the 
average. The $\mathrm{R}^{2}$ is a measure of the proportion of variance, and bias measures the difference between gauged and satellite-derived data. These indicators are defined as follows:

$$
\begin{gathered}
\mathrm{IOA}=1-\frac{\sum_{i=1}^{n}\left(M_{i}-O_{i}\right)^{2}}{\sum_{i=1}^{n}\left(\left|M_{i}-\bar{O}\right|+\left|O_{i}-\bar{O}\right|\right)^{2}} \\
\mathrm{RMSE}=\sqrt{\frac{1}{n} \sum_{i=1}^{n}\left(M_{i}-O_{i}\right)^{2}} \\
\text { MAE }=\frac{1}{n} \sum_{i=1}^{n}\left|M_{i}-O_{i}\right| \\
\mathrm{R}^{2}=\frac{\sum_{i=1}^{n}\left(O_{i}-\bar{O}\right) \times\left(M_{i}-\bar{M}\right)}{\sqrt{\sum_{i=1}^{n}\left(O_{i}-\bar{O}\right)^{2} \times\left(M_{i}-\bar{M}\right)^{2}}} \\
\text { Bias }=\frac{1}{n} \sum_{i=1}^{n}\left(M_{i}-O_{i}\right),
\end{gathered}
$$

where $M_{i}$ is the estimated grid-scale precipitation from satellite products (that is, TRMM, PERSIANN, PERSIANN-CDR, and CMADS); $O_{i}$ are ground-based measurement data; $\bar{O}$ and $\bar{M}$ are the average values of ground-based measurements and satellite precipitation data, respectively; and $n$ is the total number of data.

The suitability of satellite-derived rainfall data for the streamflow simulation was evaluated using the Nash-Sutcliffe efficiency (NSE), $\mathrm{R}^{2}$, and percent bias (PBIAS), which are widely used performance measures in hydrologic studies [58]. NSE is a normalized statistic that determines the relative magnitude of the residual variance compared to the measured data variance, and PBIAS measures the average tendency of the estimated data to be larger or smaller than their observed counterparts.

$$
\begin{gathered}
\text { NSE }=1-\left[\frac{\sum_{i=1}^{n}\left(O_{i}-P_{i}\right)^{2}}{\sum_{i=1}^{n}\left(O_{i}-\bar{O}\right)^{2}}\right] \\
\mathrm{R}^{2}=\frac{\sum_{i=1}^{n}(O-\bar{O}) \times(P-\bar{P})}{\sqrt{\sum_{i=1}^{n}(O-\bar{O})^{2} \times(P-\bar{P})^{2}}} \\
\text { PBIAS }=100 \cdot \frac{\sum_{i=1}^{n}\left(O_{i}-P_{i}\right)}{\sum_{i=1}^{n} O_{i}}
\end{gathered}
$$

where $O_{i}$ is the $i$ th observation; $P_{i}$ is the $i$ th predicted value; $\bar{O}$ and $\bar{P}$ are the mean observed and predicted values, respectively; and $n$ is the total number of observations.

\section{Results}

\subsection{Evaluation of Different Satellite-Derived Precipitation Data}

In this study, the applicability of four satellite-derived precipitation datasets (2008-2013), that is, from TRMM 3B42 V7, PERSIANN, PERSIANN-CDR, and CMADS, were evaluated. 
First, these satellite-based rainfall data were estimated and compared with gauged rainfall data. The contingency measures of the POD, PC, and FBI were used for categorical data analysis. Unlike gauged rainfall data that can be measured in a quantitative manner, it is difficult to determine the threshold for the precipitation and non-precipitation events of satellite-based rainfall data. Based on the studies by Dai [59] and Dinku et al. [60], a minimum threshold of $1.0 \mathrm{~mm}$ per day was used to discriminate between rain $(\geq 1.0 \mathrm{~mm} /$ day $)$ and no rain $(<1.0 \mathrm{~mm} /$ day). Figure 2 shows the statistical measures calculated for the four satellite-based precipitation datasets. With respect to the POD values, TRMM has the largest POD with an average of 0.73 (ranging from 0.21 to 0.88 ), which is closest to the perfect score of 1 . The CMADS has a slightly higher POD than PERSIANN, with a mean of 0.62 (ranging from 0.47 to 0.76 ), while the PERSIANN mean is 0.58 (ranging from 0.44 to 0.75 ). The PERSIANN-CDR has the smallest POD with a mean of 0.52 (ranging from 0.21 to 0.75 ; Figure 2a). With respect to the PC values, TRMM shows the best performance, with an average of 0.78 (ranging from 0.71 to 0.89 ) and CMADS has the second-best performance, with an average of 0.70 (ranging from 0.56 to 0.82 ). The mean PERSIANN and PERSIANN-CDR values are 0.60 (ranging from 0.40 to 0.77 ) and 0.50 (ranging from 0.24 to 0.69 ), respectively (Figure 2b). With respect to the FBI values, TRMM has an average value of 2.0 (ranging from 1.50 to 3.0), which is the smallest value and closest to the perfect score of 1 . The average FBI of CMADS is 2.75 , ranging from 1.25 to 4.25 . The PERSIANN and PERSIANN-CDR averages are 2.75 (ranging from 1.50 to 5.50) and 4.50 (ranging from 1.85 to 5.54), respectively (Figure 2c). These results indicate that the TRMM data show the best agreement with the gauged data, while the PERSIANN-CDR data display the biggest difference from the gauged data.

The TRMM has an average IOA value of 0.30 (ranging from 0.25 to 0.37 ). The CMADS has a slightly bigger average value of 0.32 (ranging from 0.21 to 0.34 ). The PERSIANN and PERSIANN-CDR have relatively lower mean values of 0.24 (ranging from 0.20 to 0.26 ) and 0.23 (ranging from 0.19 to 0.26 ), respectively (Figure 2d). Therefore, the average IOA of CMADS is the closest to the perfect value of 1 . The average RMSEs of the TRMM, CMADS, PERSIANN, and PERSIANN-CDR are $11.22 \mathrm{~mm} /$ day (ranging from $2.15 \mathrm{~mm} /$ day to $21.29 \mathrm{~mm} /$ day), $10.72 \mathrm{~mm} /$ day (ranging from $2.05 \mathrm{~mm} /$ day to $17.47 \mathrm{~mm} /$ day), $11.61 \mathrm{~mm} /$ day (ranging from $1.81 \mathrm{~mm} /$ day to $22.53 \mathrm{~mm} /$ day), and $11.35 \mathrm{~mm}$ /day (ranging from $1.04 \mathrm{~mm} /$ day to $22.46 \mathrm{~mm} /$ day), respectively (Figure 2e). This shows that the four satellite-based rainfall datasets have similar RMSE averages and ranges. The average MAE of the CMADS is $3.53 \mathrm{~mm} /$ day (ranging from $1.52 \mathrm{~mm} /$ day to $4.80 \mathrm{~mm} /$ day), which is smaller than that of the TRMM, PERSIANN, and PERSIANN-CDR, with average values of $3.96 \mathrm{~mm} /$ day (ranging from $2.75 \mathrm{~mm} /$ day to $5.0 \mathrm{~mm} /$ day), $3.80 \mathrm{~mm} /$ day (ranging from $2.01 \mathrm{~mm} /$ day to $5.25 \mathrm{~mm} /$ day), and $3.84 \mathrm{~mm} /$ day (ranging from $2.0 \mathrm{~mm} /$ day to $5.30 \mathrm{~mm} /$ day), respectively (Figure 2f). In Figure 2, it is difficult to see whether the RMSEs (Figure 2e) and MAE (Figure 2f) of each satellite rainfall data are significantly different. In order to determine if there are significant differences among the mean RMSEs and the mean MAEs of the four satellite rainfall data, one-way Analysis of Variance (ANOVA) was carried out. The results of ANOVA showed that the mean RMSEs of the four satellites' rainfall data are not significantly different $(p$-value $=0.692)$ at a confidence level of 0.05 . However, the $p$-value for MAE was 0.013 , which is smaller than 0.05 , and the multiple comparisons showed that the mean MAE of CMADS is significantly greater than that of TRMM. Based on the average IOA, RMSE, and MAE values, the CMADS data show the best accuracy when compared with the gauged data.

The spatial correlation and bias patterns of the four satellite-derived rainfall datasets for the quantitative verification of precipitation are illustrated in Figures 3 and 4. Overall, the TRMM shows a better correlation (average of 0.58 , ranging from 0.16 to 0.80 ) with the gauged data and a smaller bias pattern (ranging from $-5.1 \mathrm{~mm} /$ day to $4.0 \mathrm{~mm} /$ day) for most gauges, which indicates that the TRMM data are similar to the gauge observations. The average $\mathrm{R}^{2}$ of the CMADS data is 0.52 , which is slightly smaller than that of the TRMM data. The bias of the CMADS data varies between $-5.3 \mathrm{~mm} /$ day and $6.0 \mathrm{~mm} /$ day. The average $\mathrm{R}^{2}$ of the PERSIANN and PERSIANN-CDR data is 0.41 (ranging from 0.20 to 0.58 ) and 0.46 (ranging from 0.22 to 0.61 ), respectively, and the bias varies between $-5.3 \mathrm{~mm} / \mathrm{da}$ and $7.1 \mathrm{~mm} /$ day, and between $-5.5 \mathrm{~mm} /$ day and $7.9 \mathrm{~mm} /$ day, respectively. 

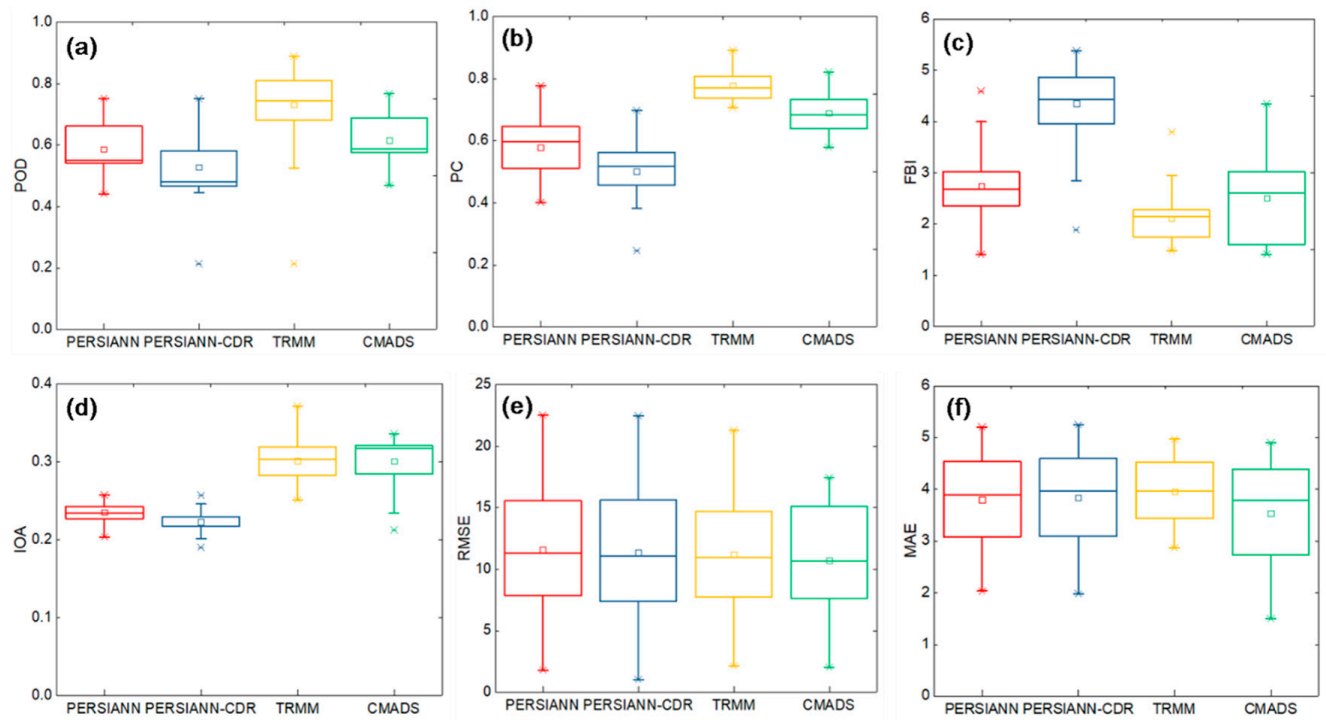

Figure 2. The box plots for the statistical measures of (a) probability of detection (POD), (b) proportion correct (PC), (c) frequency bias index (FBI), (d) index of agreement (IOA), (e) root mean square error (RMSE), and (f) mean absolute error (MAE). The square symbol represents the mean value. The median is presented by the middle line in the box. Each box ranges from the lower (25th) to upper quartile (75th).

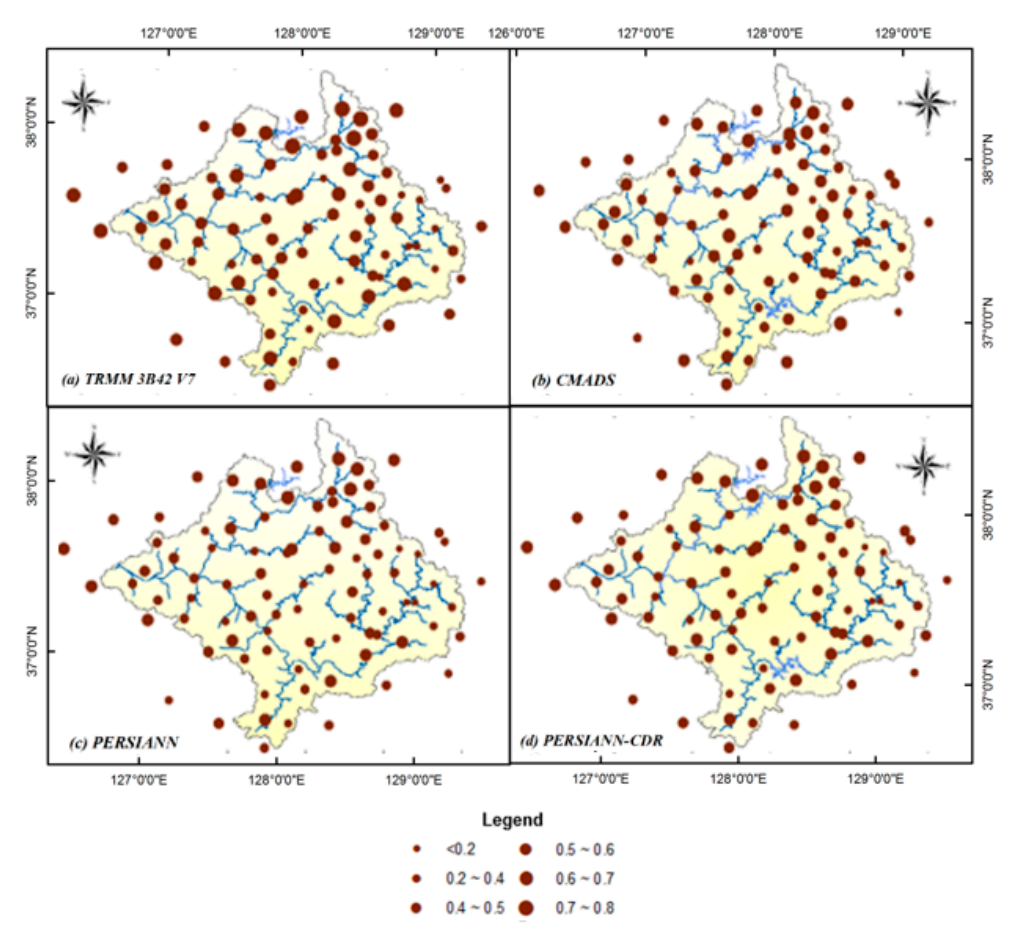

Figure 3. The spatial correlation pattern for ground-based and satellite-derived rainfall during 2008-2013. The circles represent the gauge stations. (a) TRMM 3B42 V7, (b) CMADS, (c) PERSIANN, (d) PERSIANN-CDR. 


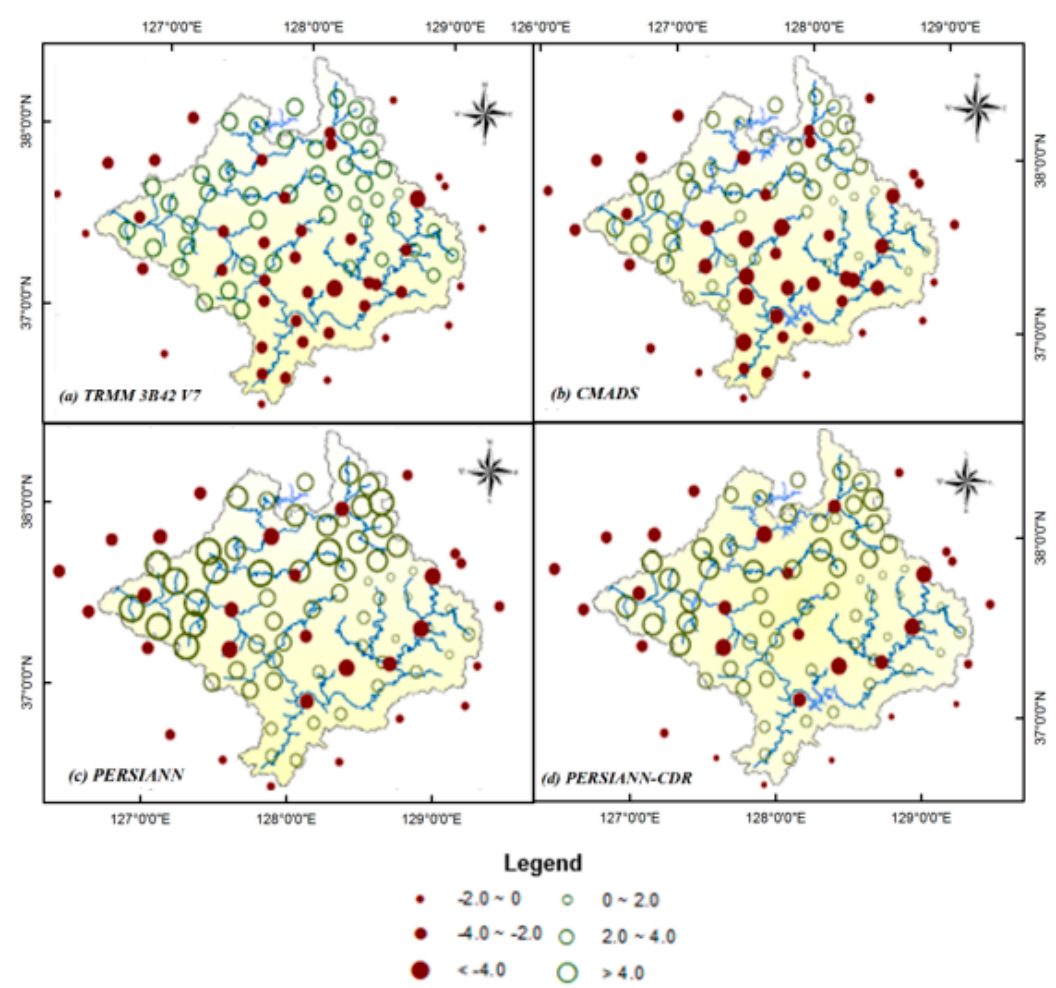

Figure 4. The spatial bias pattern for ground-based and satellite-derived rainfall during 2008-2013. The circles represent the gauge stations. (a) TRMM 3B42 V7, (b) CMADS, (c) PERSIANN, (d) PERSIANN-CDR.

\subsection{SWAT Calibration and Validation}

The SWAT model was calibrated and validated using gauged precipitation as model input. The simulated streamflow was then compared to the data observed at 16 stream gauges that are distributed near homogeneously and have no missing data. A sensitivity analysis was used to identify the key parameters required for model calibration [61]. Six parameters, that is, CN2, ALPHA_BF, CH_K2,CH_N2,CANMX, and CH_N1, were selected to calibrate the model. The initial and calibrated values of those six parameters are shown in Table 4. An automated baseflow separation technique was used [31] to obtain a more reasonable ALPHA BF (ratio of surface runoff to baseflow) value for the Han River Basin. Based on the obtained values of ALPHA_BF at different streamflow stations, the initial range of ALPHA_BF was set for the SWAT model calibration. The calibration (2008-2010) and validation (2011-2013) were performed using the SUFI-2 algorithm. The objective function of the SWAT model calibration is to maximize the NSE. The distribution of behavioral model parameters (1000 runs) for the model calibration is shown in Figure 5. Figure 5 shows that most of the identified parameters are distributed with the NSE ranging from 0.4 to 0.6 . The statistical measures for model performances computed using daily streamflow observations are listed in Table 5 . The results show an overall good agreement between the observed and simulated streamflow; the NSE, $\mathrm{R}^{2}$, and PBIAS values vary in the ranges of 0.50 to $0.94,0.51$ to 0.95 , and $-14.10 \%$ to $24.30 \%$, respectively, during the calibration and from 0.50 to $0.90,0.51$ to 0.90 , and $-38.80 \%$ to $21.47 \%$, respectively, during the validation. The NSE, $R^{2}$, and PBIAS values at the outlet of the basin (Haengjudaegyo Station) are $0.58 \%, 0.59 \%$, and $-10.00 \%$, respectively, during the model calibration and $0.77 \%, 0.81 \%$, and $-38.80 \%$, respectively, during the model validation. 
Table 4. The initial and calibrated parameters selected for the SWAT model.

\begin{tabular}{ccccc}
\hline Parameters & Parameter Description & Initial Range & Calibrated Range & Best Value \\
\hline r CN2 & Initial SCS CN II value & -0.20 to 0.20 & -0.07 to 0.79 & 0.18 \\
${ }^{v}$ ALPHA_BF & Baseflow alpha factor & 0.0035 to 0.80 & 0.28 to 0.80 & 0.72 \\
v CH_K2 & Effective hydraulic conductivity of the main channel & -0.01 to 500 & -0.01 to 268 & 4.65 \\
v CH_N2 & Manning's value for main channels & -0.01 to 0.30 & -0.10 to 0.17 & 0.03 \\
v CANMX & Maximum canopy storage & 0 to 100 & 0 to 55.40 & 55.19 \\
v CH_N1 & Manning's value for tributary channels & 0.01 to 30 & 10 to 30 & 28.46 \\
\hline
\end{tabular}

${ }^{\mathrm{r}}$ The parameter was multiplied by one plus a given value; ${ }^{\mathrm{v}}$ The parameter was replaced by a given value.
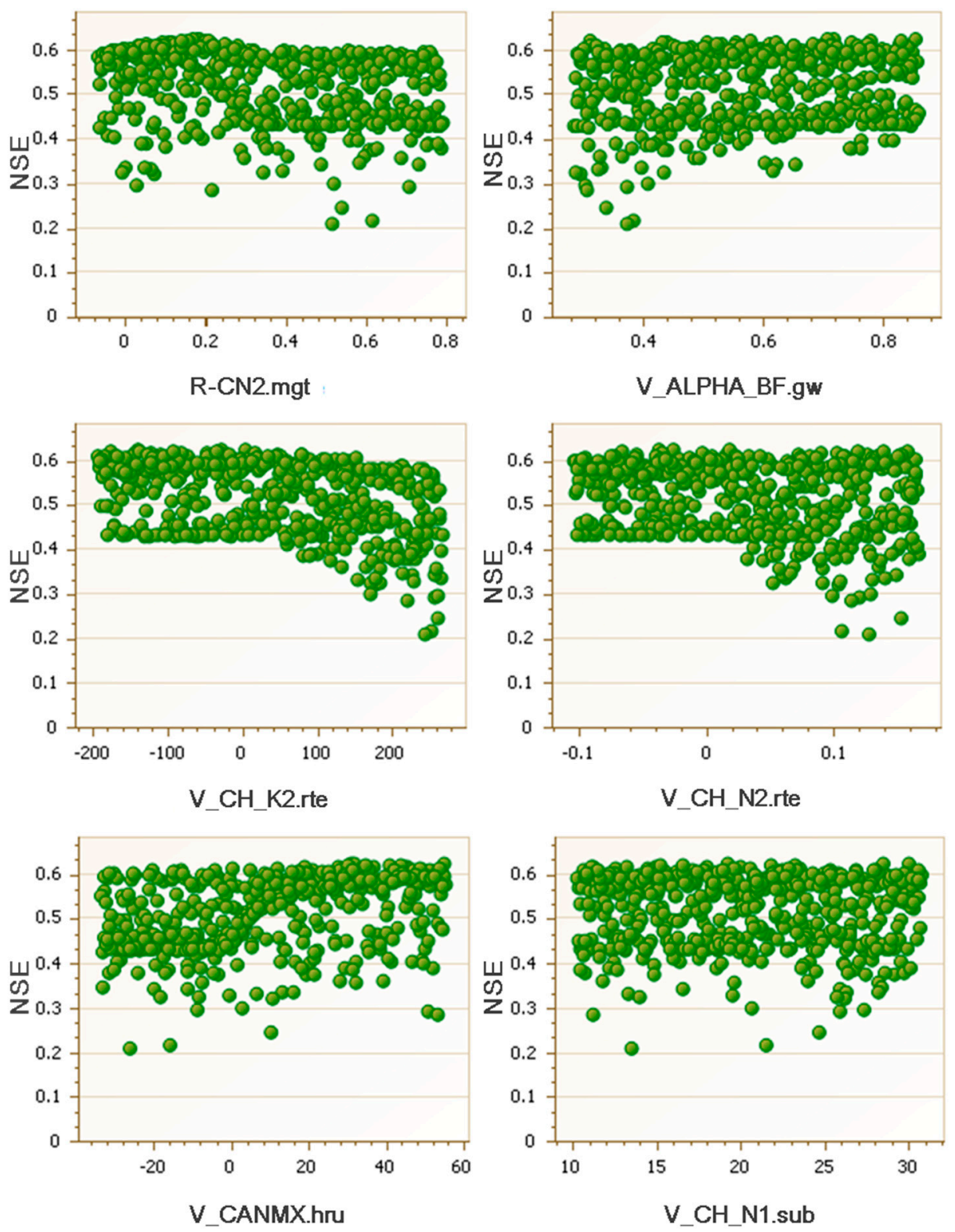

Figure 5. The distribution of behavioral model parameters. 
Table 5. The statistical measurements of the model performance for the streamflow simulation.

\begin{tabular}{cccccccc}
\hline \multirow{2}{*}{ Code } & \multirow{2}{*}{ Station } & \multicolumn{2}{c}{ Calibration (2008-2010) } & \multicolumn{2}{c}{ Validation (2011-2013) } \\
\cline { 3 - 7 } & & NSE & $\mathbf{R}^{\mathbf{2}}$ & PBIAS (\%) & NSE & $\mathbf{R}^{\mathbf{2}}$ & PBIAS (\%) \\
\hline SG6 & PanUn & 0.53 & 0.54 & -7.50 & - & - & - \\
SG8 & YeongWeol1 & 0.57 & 0.59 & 14.70 & 0.64 & 0.72 & -33.41 \\
SG9 & YeongChun & 0.59 & 0.59 & 3.50 & 0.61 & 0.71 & -26.99 \\
SG10 & DalCheon & 0.63 & 0.67 & 24.30 & 0.75 & 0.78 & -17.19 \\
SG11 & Mokgyegyo & 0.94 & 0.95 & 14.70 & 0.61 & 0.73 & -10.10 \\
SG15 & Yeojudaegyo & 0.82 & 0.82 & -0.20 & - & - & - \\
SG17 & Heukcheongyo & 0.51 & 0.53 & 20.00 & 0.61 & 0.61 & -7.73 \\
SG19 & WeonTong & 0.53 & 0.67 & 11.30 & 0.50 & 0.51 & 21.47 \\
SG20 & NaeLinCheon & 0.69 & 0.70 & 17.10 & 0.58 & 0.66 & -12.44 \\
SG23 & Jueumchigyo & 0.50 & 0.51 & 16.90 & 0.56 & 0.56 & 18.90 \\
SG25 & Bangokgyo & 0.67 & 0.71 & 24.20 & 0.58 & 0.63 & -6.78 \\
SG26 & Daeseongri & 0.71 & 0.73 & 0.60 & 0.61 & 0.73 & -14.71 \\
SG28 & Sumthlgyo & 0.63 & 0.67 & 20.50 & 0.75 & 0.78 & 20.77 \\
SG31 & Gwangjingyo & 0.56 & 0.63 & -14.10 & 0.56 & 0.77 & -24.96 \\
SG33 & Jungranggyo & 0.56 & 0.58 & 18.40 & 0.90 & 0.90 & -11.80 \\
SG37 (outlet) & Haengjudaegyo & 0.58 & 0.59 & -13.00 & 0.77 & 0.81 & -38.80 \\
\hline
\end{tabular}

\subsection{Streamflow Simulation Using Four Satellite-Derived Rainfall Datasets}

The SWAT model calibrated using ground-based rainfall data was used for the evaluation of the hydrologic performance of four satellite-derived rainfall products. Propagation of the uncertainties in the parameters leads to uncertainties in the model output, that is, the discharge of the streamflow, which are expressed as the $95 \%$ probability distributions. These are calculated at the $2.5 \%$ and $97.5 \%$ levels of the cumulative distribution of the discharge. This is referred to as the $95 \%$ prediction uncertainty, or 95PPU. Figures 6-10 illustrate the prediction uncertainty at the outlet (Haengjudaegyo station) of the Han River Basin from May to October 2008. These figures show that the TRMM rainfall data have a better performance than other satellite rainfall data in streamflow simulations.

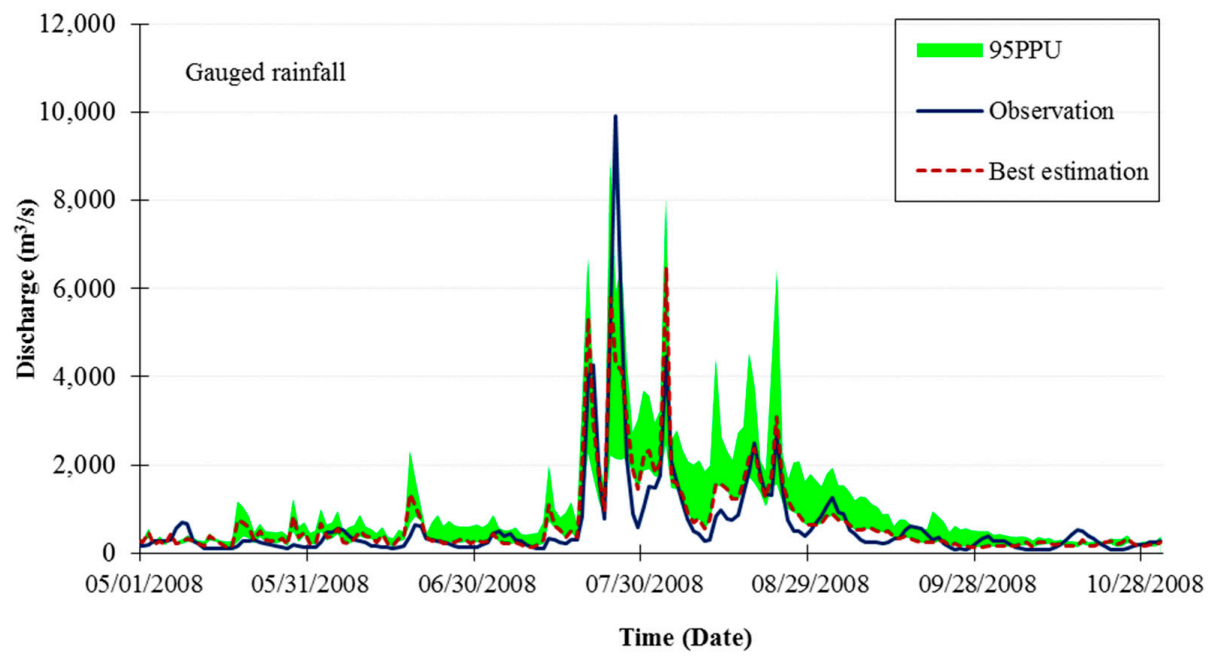

Figure 6. The $95 \%$ prediction uncertainty (95PPU) for streamflow simulations using gauged rainfall from May to October (2008). 


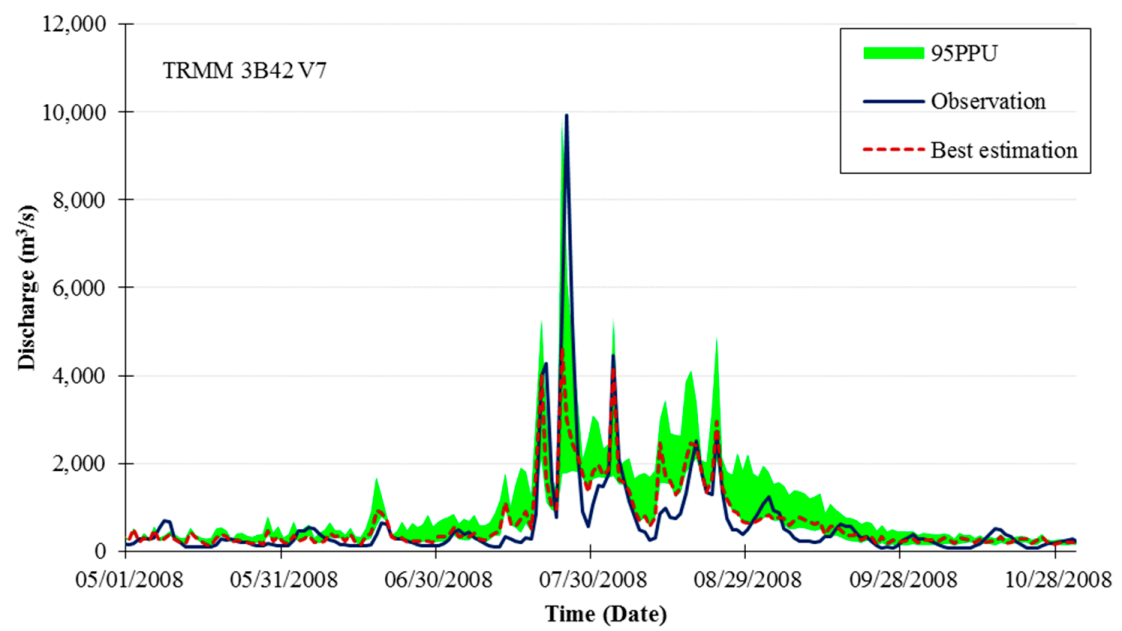

Figure 7. The 95PPU for streamflow simulations using Tropical Rainfall Measuring Mission (TRMM 3B42 V7) rainfall estimates from May to October (2008).

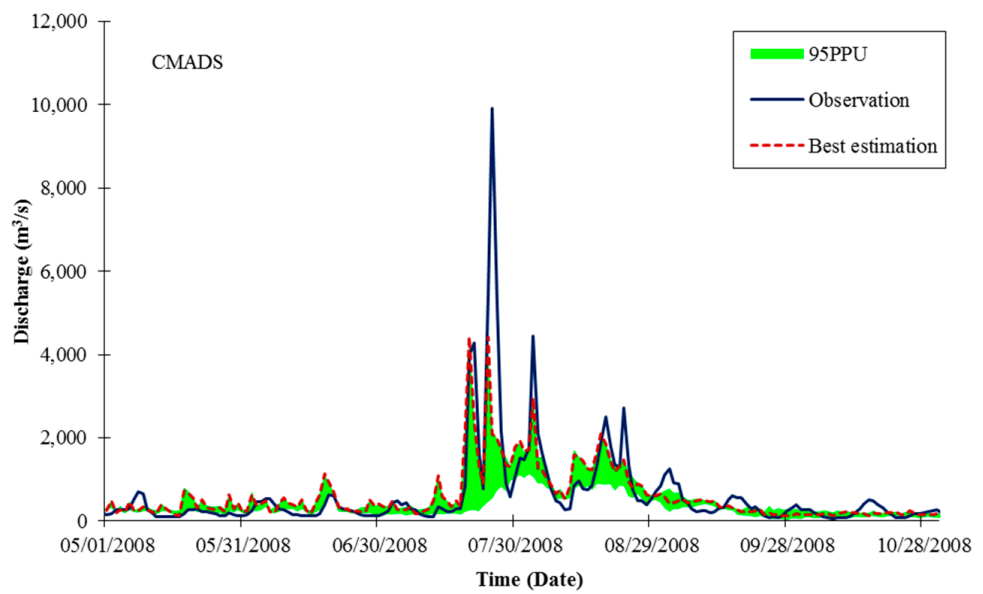

Figure 8. The 95PPU for streamflow simulations using China Meteorological Assimilation Driving Datasets for the SWAT Model (CMADS) rainfall estimates from May to October (2008).

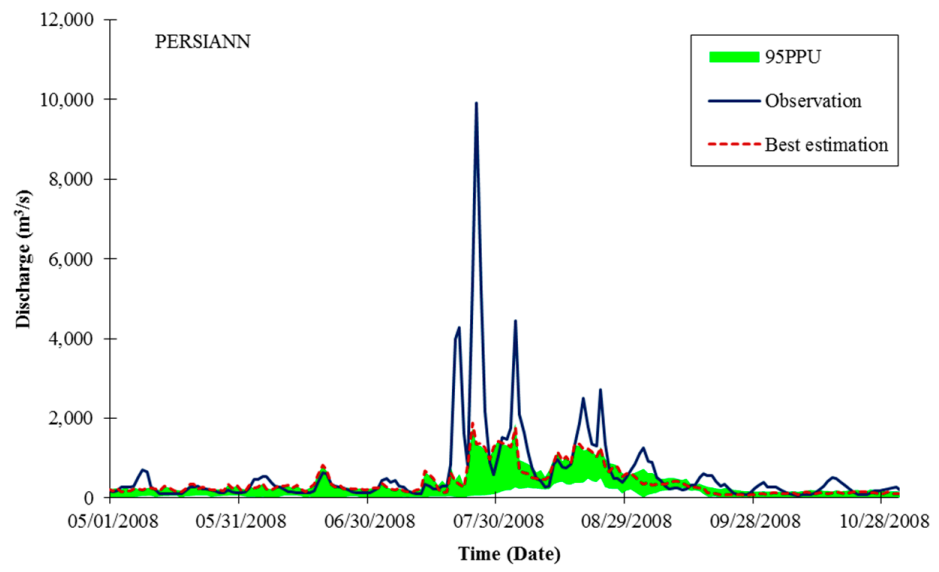

Figure 9. The 95PPU for streamflow simulations using Precipitation Estimation from Remotely Sensed Information using Artificial Neural Networks (PERSIANN) rainfall estimates from May to October (2008). 


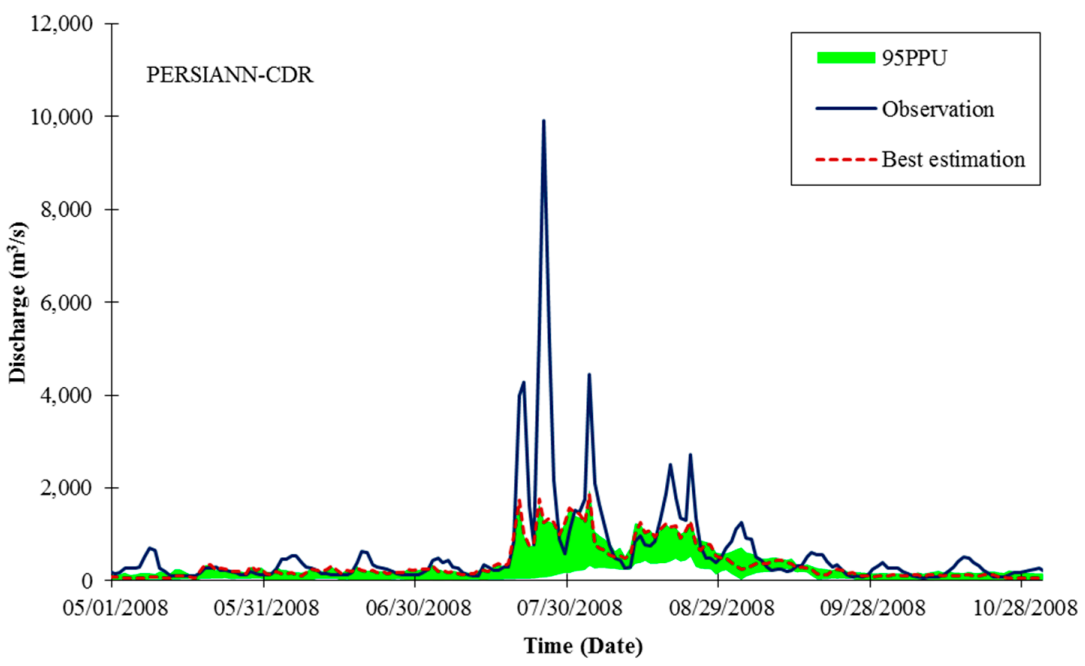

Figure 10. The 95PPU for streamflow simulations using PERSIANN-Climate Data Record (PERSIANN-CDR) rainfall estimates from May to October (2008).

To quantify the fit between the simulation results, expressed as 95PPU, and the observations, the P-factor and R-factor were calculated. The P-factor is the percentage of observed data enveloped by the out modeling result, the 95PPU. The R-factor is the thickness of the 95PPU envelope. A P-factor of 1 and an R-factor of zero is a simulation that exactly corresponds to the measured data. The two statistics for simulations using gauged rainfall and satellite rainfall estimates are shown in Table 6.

Table 6. The P-factor and R-factor due to different rainfall datasets.

\begin{tabular}{ccccccc}
\hline Statistics & $\begin{array}{c}\text { Gauged Rainfall } \\
\text { (Calibration) }\end{array}$ & $\begin{array}{c}\text { Gauged Rainfall } \\
\text { (Validation) }\end{array}$ & TRMM & CMADS & PERSIANN & PERSIANN-CDR \\
\hline P-factor & 0.54 & 0.47 & 0.51 & 0.40 & 0.39 & 0.33 \\
R-factor & 0.47 & 0.56 & 0.42 & 0.42 & 0.37 & 0.43 \\
\hline
\end{tabular}

Table 7 shows that the daily streamflow simulation using TRMM data, with an average $\mathrm{R}^{2}$ of 0.54 (ranging from 0.29 to 0.81 ), average NSE of 0.49 (ranging from 0.27 to 0.79 ), and the PBIAS ranging from $-52.70 \%$ to $28.30 \%$, performs better than the simulations using the other three satellite-derived rainfall datasets. The streamflow simulation using the CMADS data shows the second-best performance, with an average $\mathrm{R}^{2}$ of 0.44 (ranging from 0.22 to 0.70 ), average NSE of 0.42 (ranging from 0.3 to 0.62 ), and the PBIAS ranging from $-29.3 \%$ to $41.8 \%$. The average $\mathrm{R}^{2}$, NSE, and PBIAS show that models using the PERSIANN and PERSIANN-CDR perform relatively poor.

Table 7. The statistical indicators for the streamflow simulations using different rainfall datasets.

\begin{tabular}{cccccc}
\hline Code & Station & Product & $\mathbf{R}^{\mathbf{2}}$ & NSE & PBIAS (\%) \\
\hline \multirow{4}{*}{ SG6 } & \multirow{3}{*}{ PanUn } & Rain gauge & 0.54 & 0.53 & -7.50 \\
& & PERSIANN & 0.44 & 0.23 & 55.70 \\
& & PERSIANN-CDR & 0.21 & 0.19 & 35.00 \\
& & TRMM 3B42 V7 & 0.48 & 0.42 & -52.70 \\
& & CMADS & 0.39 & 0.37 & 11.20 \\
\hline \multirow{3}{*}{ SG8 } & ReongWeol1 & Rain gauge & 0.66 & 0.61 & -9.36 \\
& & PERSIANN & 0.55 & 0.21 & 67.20 \\
& & TRMM 3B42 V7 & 0.46 & 0.45 & -18.40 \\
& & CMADS & 0.49 & 0.43 & 23.20 \\
\hline
\end{tabular}


Table 7. Cont.

\begin{tabular}{|c|c|c|c|c|c|}
\hline Code & Station & Product & $\mathbf{R}^{2}$ & NSE & PBIAS (\%) \\
\hline \multirow{5}{*}{ SG9 } & \multirow{5}{*}{ YeongChun } & Rain gauge & 0.65 & 0.60 & -11.75 \\
\hline & & PERSIANN & 0.49 & 0.25 & 59.50 \\
\hline & & PERSIANN-CDR & 0.28 & 0.25 & 31.30 \\
\hline & & TRMM 3B42 V7 & 0.59 & 0.54 & -33.00 \\
\hline & & CMADS & 0.44 & 0.42 & 20.90 \\
\hline \multirow{5}{*}{ SG10 } & \multirow{5}{*}{ DalCheon } & Rain gauge & 0.73 & 0.69 & 3.56 \\
\hline & & PERSIANN & 0.41 & 0.15 & 68.90 \\
\hline & & PERSIANN-CDR & 0.29 & 0.23 & 46.30 \\
\hline & & TRMM 3B42 V7 & 0.33 & 0.33 & -14.80 \\
\hline & & CMADS & 0.36 & 0.33 & 10.10 \\
\hline \multirow{5}{*}{ SG11 } & \multirow{5}{*}{ Mokgyegyo } & Rain gauge & 0.84 & 0.78 & 2.30 \\
\hline & & PERSIANN & 0.61 & 0.18 & 71.10 \\
\hline & & PERSIANN-CDR & 0.60 & 0.42 & 50.10 \\
\hline & & TRMM 3B42 V7 & 0.81 & 0.79 & -7.30 \\
\hline & & CMADS & 0.70 & 0.62 & 35.50 \\
\hline \multirow{5}{*}{ SG15 } & \multirow{5}{*}{ Yeojudaegyo } & Rain gauge & 0.82 & 0.82 & -0.20 \\
\hline & & PERSIANN & 0.06 & 0.04 & 40.50 \\
\hline & & PERSIANN-CDR & 0.05 & 0.03 & 31.20 \\
\hline & & TRMM 3B42 V7 & 0.60 & 0.43 & -13.57 \\
\hline & & CMADS & 0.31 & 0.31 & -29.30 \\
\hline \multirow{5}{*}{ SG17 } & \multirow{5}{*}{ Heukcheongyo } & Rain gauge & 0.57 & 0.56 & 6.14 \\
\hline & & PERSIANN & 0.08 & 0.03 & 69.90 \\
\hline & & PERSIANN-CDR & 0.06 & 0.03 & 58.80 \\
\hline & & TRMM 3B42 V7 & 0.48 & 0.42 & 12.70 \\
\hline & & CMADS & 0.30 & 0.38 & 41.80 \\
\hline \multirow{5}{*}{ SG19 } & \multirow{5}{*}{ WeonTong } & Rain gauge & 0.59 & 0.52 & 16.39 \\
\hline & & PERSIANN & 0.40 & 0.04 & 83.20 \\
\hline & & PERSIANN-CDR & 0.44 & 0.17 & 71.20 \\
\hline & & TRMM 3B42 V7 & 0.59 & 0.58 & 28.30 \\
\hline & & CMADS & 0.57 & 0.49 & 27.10 \\
\hline \multirow{5}{*}{ SG20 } & \multirow{5}{*}{ NaeLinCheon } & Rain gauge & 0.68 & 0.64 & 2.33 \\
\hline & & PERSIANN & 0.32 & 0.12 & 72.60 \\
\hline & & PERSIANN-CDR & 0.23 & 0.17 & 54.10 \\
\hline & & TRMM 3B42 V7 & 0.59 & 0.58 & -4.50 \\
\hline & & CMADS & 0.31 & 0.45 & 19.50 \\
\hline \multirow{5}{*}{ SG23 } & \multirow{5}{*}{ Jueumchigyo } & Rain gauge & 0.52 & 0.51 & 17.90 \\
\hline & & PERSIANN & 0.04 & 0.02 & 73.80 \\
\hline & & PERSIANN-CDR & 0.04 & 0.02 & 59.90 \\
\hline & & TRMM 3B42 V7 & 0.58 & 0.42 & 11.30 \\
\hline & & CMADS & 0.50 & 0.43 & 22.90 \\
\hline \multirow{5}{*}{ SG25 } & \multirow{5}{*}{ Bangokgyo } & Rain gauge & 0.67 & 0.63 & 8.71 \\
\hline & & PERSIANN & 0.14 & 0.02 & 73.70 \\
\hline & & PERSIANN-CDR & 0.08 & 0.02 & 62.00 \\
\hline & & TRMM 3B42 V7 & 0.56 & 0.55 & 16.00 \\
\hline & & CMADS & 0.47 & 0.41 & 20.70 \\
\hline \multirow{5}{*}{ SG26 } & \multirow{5}{*}{ Daeseongri } & Rain gauge & 0.73 & 0.66 & -7.06 \\
\hline & & PERSIANN & 0.45 & 0.35 & 48.90 \\
\hline & & PERSIANN-CDR & 0.50 & 0.44 & 36.00 \\
\hline & & TRMM 3B42 V7 & 0.55 & 0.51 & -8.90 \\
\hline & & CMADS & 0.53 & 0.51 & 24.30 \\
\hline
\end{tabular}


Table 7. Cont

\begin{tabular}{|c|c|c|c|c|c|}
\hline Code & Station & Product & $\mathrm{R}^{2}$ & NSE & PBIAS (\%) \\
\hline \multirow{5}{*}{ SG28 } & \multirow{5}{*}{ Sumthlgyo } & Rain gauge & 0.73 & 0.69 & 20.64 \\
\hline & & PERSIANN & 0.13 & 0.20 & 75.30 \\
\hline & & PERSIANN-CDR & 0.07 & 0.10 & 67.40 \\
\hline & & TRMM 3B42 V7 & 0.62 & 0.57 & 25.10 \\
\hline & & CMADS & 0.59 & 0.55 & 23.90 \\
\hline \multirow{5}{*}{ SG31 } & \multirow{5}{*}{ Gwangjingyo } & Rain gauge & 0.70 & 0.56 & -14.53 \\
\hline & & PERSIANN & 0.08 & 0.05 & 38.10 \\
\hline & & PERSIANN-CDR & 0.06 & 0.01 & 12.70 \\
\hline & & TRMM 3B42 V7 & 0.57 & 0.44 & -51.20 \\
\hline & & CMADS & 0.49 & 0.42 & -10.70 \\
\hline \multirow{5}{*}{ SG33 } & \multirow{5}{*}{ Jungranggyo } & Rain gauge & 0.74 & 0.73 & 3.30 \\
\hline & & PERSIANN & 0.19 & 0.04 & 75.80 \\
\hline & & PERSIANN-CDR & 0.30 & 0.15 & 62.50 \\
\hline & & TRMM 3B42 V7 & 0.29 & 0.27 & 13.40 \\
\hline & & CMADS & 0.39 & 0.30 & 21.80 \\
\hline \multirow{5}{*}{ SG37 (Outlet) } & \multirow{5}{*}{ Haengjudaegyo } & Rain gauge & 0.70 & 0.68 & -25.90 \\
\hline & & PERSIANN & 0.23 & 0.16 & 52.60 \\
\hline & & PERSIANN-CDR & 0.18 & 0.16 & 32.90 \\
\hline & & TRMM 3B42 V7 & 0.46 & 0.47 & -32.50 \\
\hline & & CMADS & 0.22 & 0.32 & 14.60 \\
\hline \multirow{5}{*}{\multicolumn{2}{|c|}{ Average }} & Rain gauge & 0.68 & 0.64 & 0.31 \\
\hline & & PERSIANN & 0.29 & 0.13 & 64.18 \\
\hline & & PERSIANN-CDR & 0.25 & 0.16 & 48.66 \\
\hline & & TRMM 3B42 V7 & 0.54 & 0.49 & -8.13 \\
\hline & & CMADS & 0.44 & 0.42 & 17.34 \\
\hline
\end{tabular}

Figure 11 shows the daily streamflow simulated by using the gauged rainfall and different satellite-derived rainfall datasets as inputs. Based on Figure 11, the models using the four satellite-based rainfall datasets capture the behavior of the streamflow in most cases by characterizing the rising and falling of flow. At SG11, SG26, SG31, and SG37, the hydrological models driven by the TRMM and CMADS data simulate the streamflow very well. However, the models using the four satellite-derived rainfall datasets tend to underestimate the peak flow of most flood events.
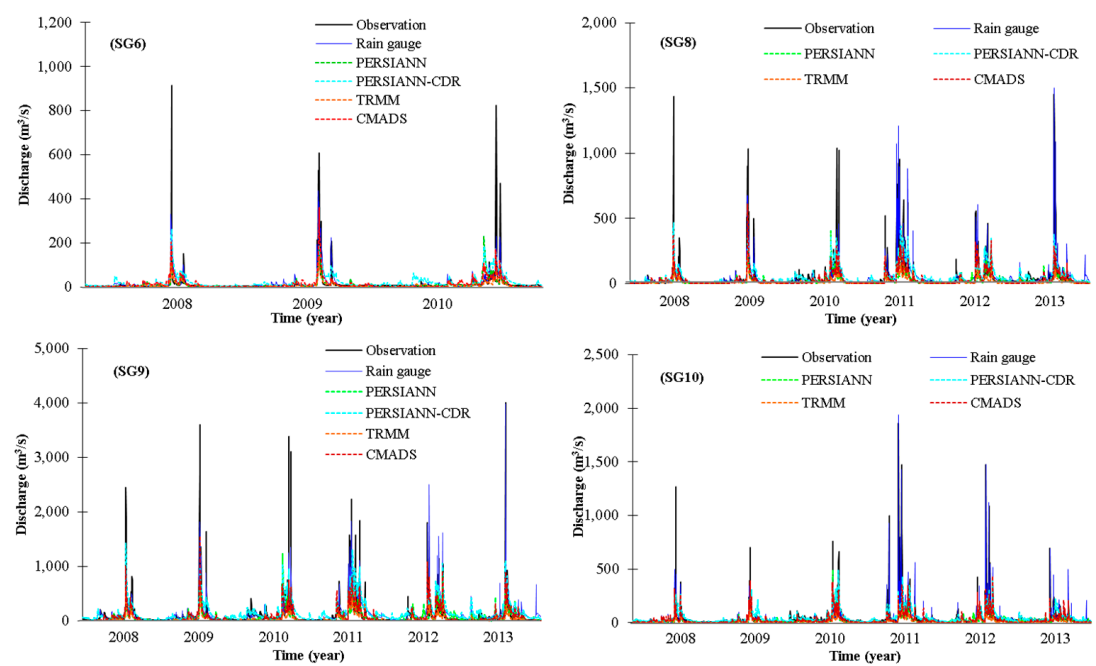

Figure 11. Cont. 

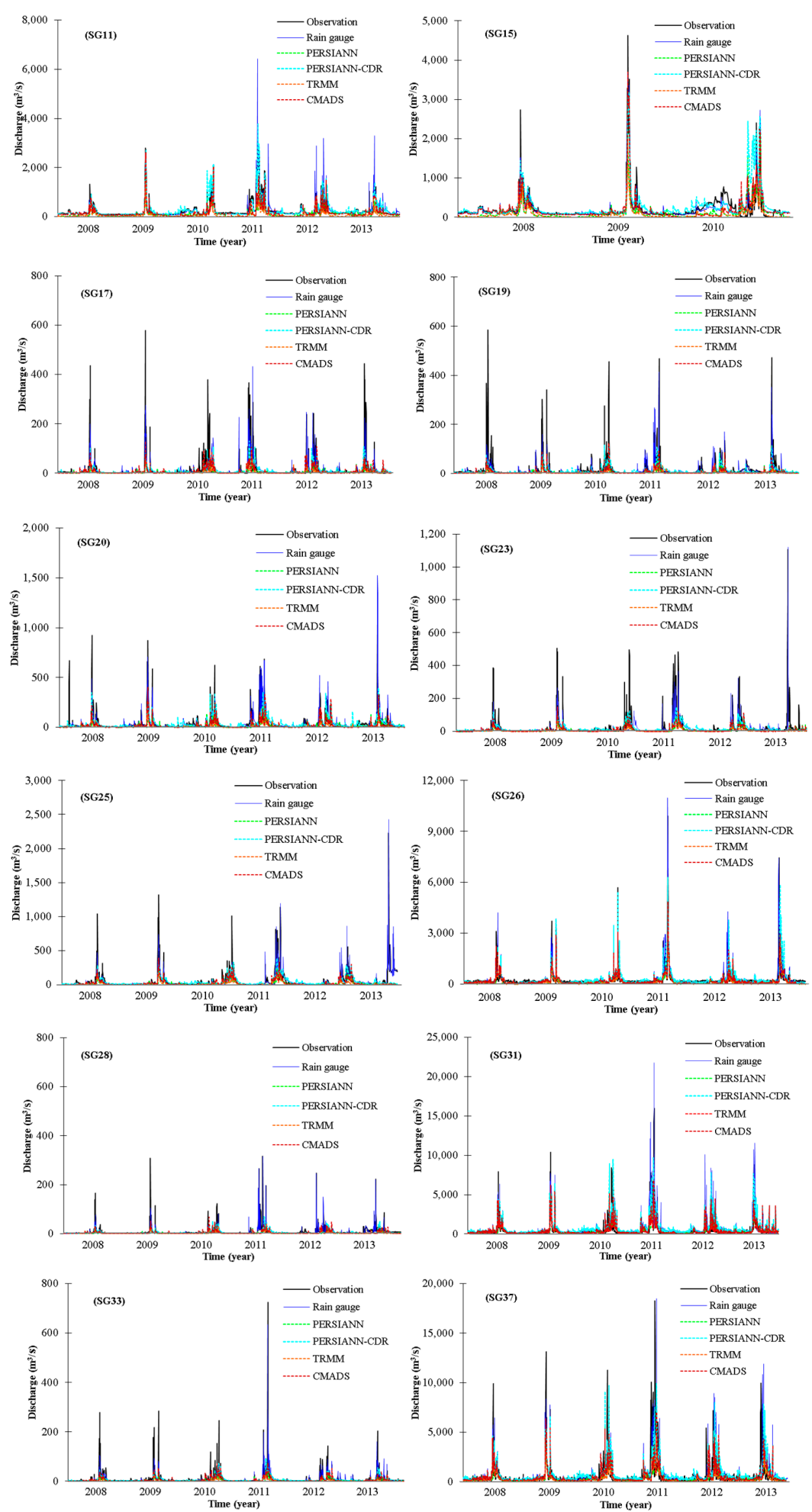

Figure 11. The comparison of the observed and computed flows obtained by using ground-based rainfall and the four satellite-derived rainfall datasets.

\section{Discussion}

Our study indicates that the TRMM and CMADS rainfall data show higher accuracy than the PERSIANN and PERSIANN-CDR data. Additionally, the models using the TRMM and CMADS data show a better performance than those using the PERSIANN and PERSIANN-CDR data for 
streamflow simulation in the Han River Basin. The results show that the PERSIANN-CDR data, which are bias-adjusted products, and the PERSIANN data have a similar accuracy. The hydrologic models using these two rainfall datasets as inputs show similar performances. Contrary to the results of this study, Ashouri et al. [49] evaluated an extreme weather event (Hurricane Katrina) in the United States and showed that PERSIANN-CDR data have a higher correlation with gauged rainfall than the TMPA data.

While the satellite rainfall data either overestimate or underestimate the gauged rainfall data at different stations due to the spatiotemporal uncertainty of satellite rainfall products, the streamflow simulation results show that the SWAT model using different satellite rainfall datasets mostly underestimates the peak flow. Figures 12-15 show the comparison of spatially averaged gauged rainfall and satellite-derived rainfall estimates, and Figure 16 shows the comparison of spatially averaged annual maximum daily rainfall. These figures show that except TRMM, the other three satellites' data tend to underestimate the spatially averaged gauged data. Therefore, the underestimation of streamflow could be attributed to the overall underestimation of satellite rainfall data. Such a tendency may or may not be only for the Han River Basin and/or for the specific period from 2008 to 2013. Hromadka and McCuen [62], Maskey et al. [63], and Jones et al. [64] indicated that one of the main sources of uncertainty in streamflow simulations using rainfall-runoff models is the spatiotemporal uncertainty of the catchment rainfall. This means that the satellite-based rainfall estimates have a significant effect on the streamflow simulation [65]. The uncertainty in satellite-based rainfall estimates can have several causes. Gebregiorgis and Hossain [66] characterized the errors of satellite-derived rainfall data based on climate type and topography (elevation). They found that the uncertainty of satellite rainfall data depends more on the topography of the region than the regional climate. $\mathrm{Xu}$ et al. [67] found that a large amount of uncertainty in a satellite precipitation dataset can be explained by the normalized difference vegetation index, digital elevation model, and land surface temperature. Bitew and Gebremichael [68] evaluated the performance of satellite rainfall products in streamflow simulations (that is, CMORPH, TMPA 3B42RT, TMPA 3B42, and PERSIANN) for two different watersheds of the Ethiopian highlands and showed that the application of different satellite rainfall products is related to the watershed area. All these factors can explain the errors in streamflow simulations using satellite-derived rainfall data. An error propagation from satellite-derived rainfall to streamflow simulation of hydrological models is inevitable. Thus, the improvement of the accuracy of satellite-derived rainfall data is very important and a systematic error correction of satellite data for hydrological applications should be considered. Several studies showed that the use of satellite data for the calibration of hydrological models results in a better streamflow prediction $[18,69]$. However, such a recalibration may fail due to errors in the satellite data, which are more difficult to control than those of ground-based data.

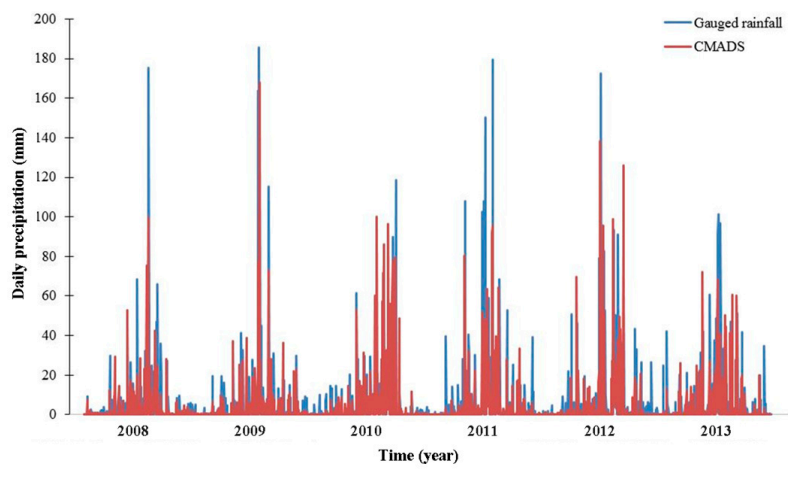

Figure 12. The comparison of spatially averaged gauged rainfall and CMADS. 


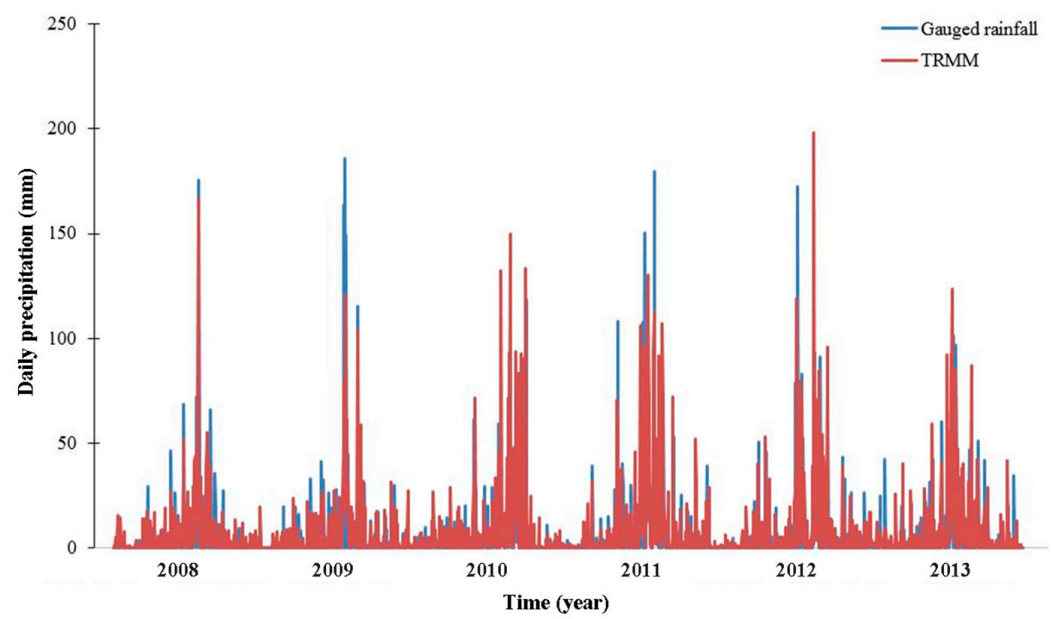

Figure 13. The comparison of spatially averaged gauged rainfall and TRMM.

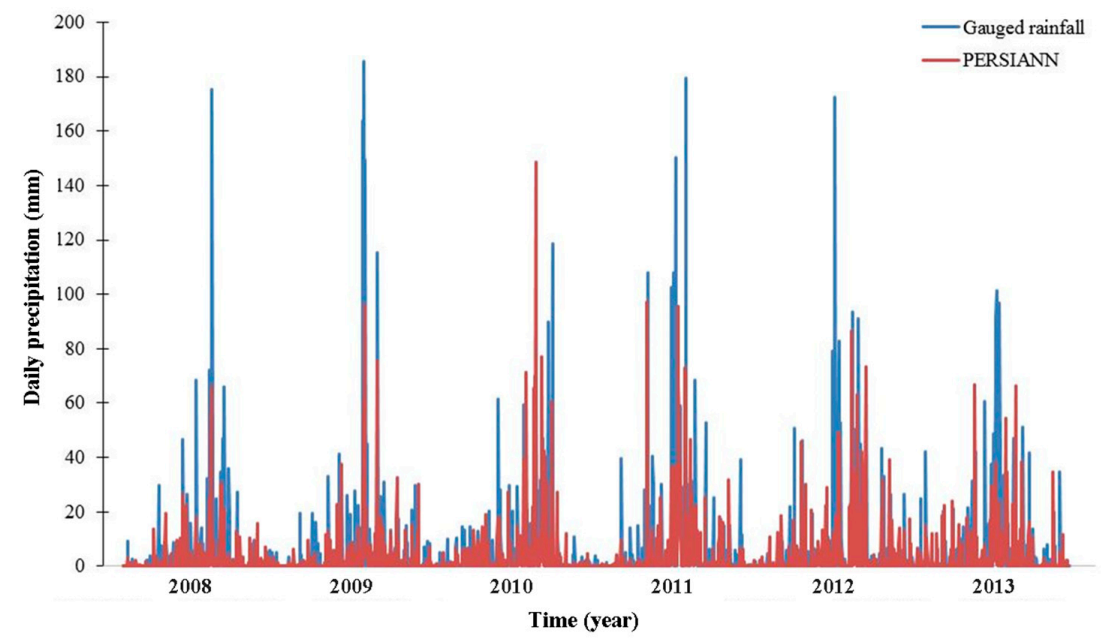

Figure 14. The comparison of spatially averaged gauged rainfall and PERSIANN.

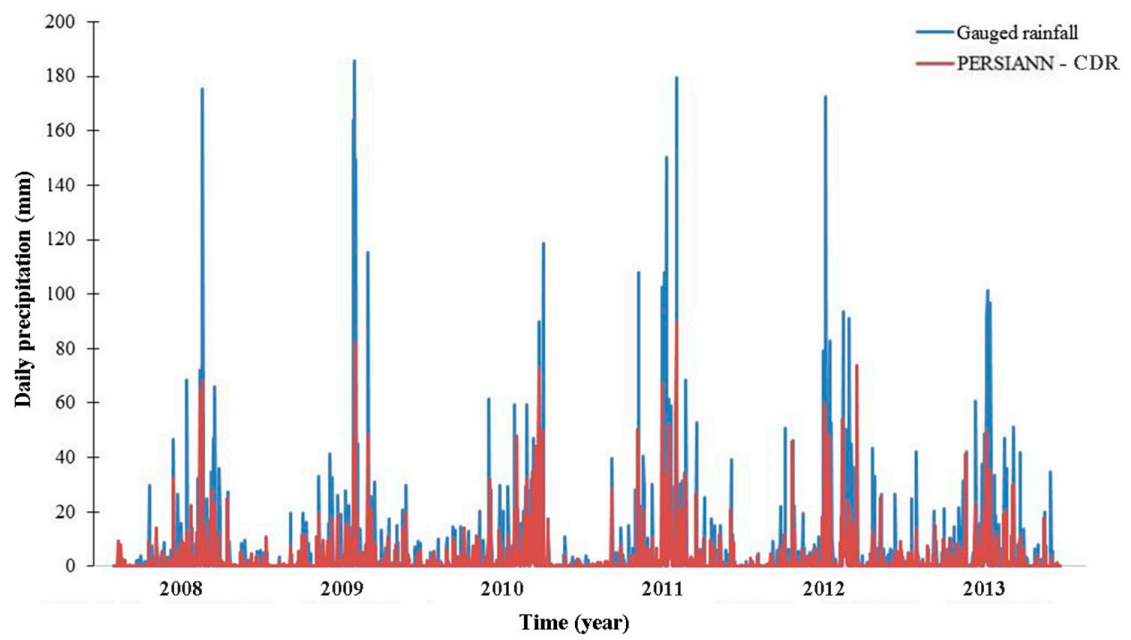

Figure 15. The comparison of spatially averaged gauged rainfall and PERSIANN-CDR. 


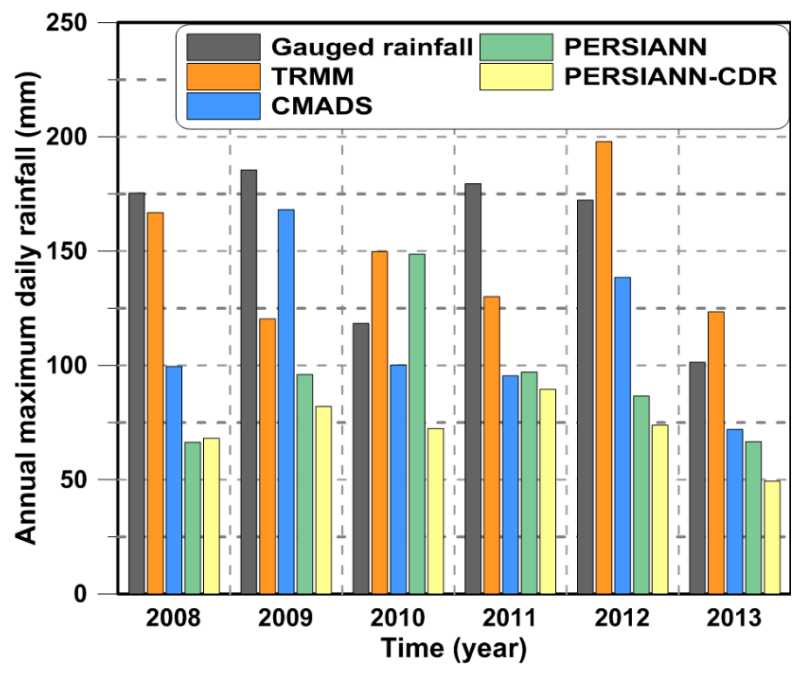

Figure 16. The comparison of annual maximum daily rainfall of different datasets.

\section{Conclusions}

The main purpose of this study was to evaluate the utility of satellite-derived precipitation data in a hydrological model for streamflow simulation in the Han River Basin. Four different satellite-derived rainfall datasets were compared with ground-based rainfall data at a daily time step. The TRMM and CMADS rainfall data have relatively higher accuracy. The runoff simulations indicate that the use of ground-based rainfall data in the SWAT model leads to an overall good agreement between observed and computed streamflow. Based on the comparison of the use of the four satellite rainfall products for streamflow simulation in the Han River Basin, hydrological models using the TRMM and CMADS rainfall data perform better than those using PERSIANN and PERSIANN-CDR data. The results of this study indicate that the TRMM and CMADS rainfall data can play significant roles in water resource management and flood control in the Han River Basin. This study also indicates that the CMADS will provide important basic data with acceptable accuracy for hydrological research in East Asia, especially in areas with scarce data.

In the study, a pixel-to-point comparison was made between satellite rainfall data and gauged data. However, a point-to-pixel comparison using some statistical interpolation methods such as multiple linear regression, optimal interpolation or Kriging should be further discussed in the future study.

One of the main purposes of the study is to evaluate the newly developed CMADS in comparison with gauged data and other satellite rainfall products. In this study, data for a limited period (2008-2013) were used since the CMADS is only available from 2008. However, from a climatological point of view, using data for only 6 years may not lead to robust results since it is too short to include all the different characteristics of the rainfall regime of the area. Using data from different periods could show different results in the rainfall data comparison as well as in the SWAT model simulation. In addition, 3-year data (2008-2010) was used for the SWAT model calibration; however, data from different periods may also produce different results. Therefore, the findings and the conclusions of this study may not be generalized for different time periods. Further studies using a longer period of data would produce more robust results.

Author Contributions: T.T.V. designed the framework and analyzed the data of this study; T.T.V. and L.L. collected the data and wrote the paper; K.S.J. provided significant suggestions on the methodology and structure of the manuscript. All authors read and approved the final manuscript.

Funding: This research was funded by Ministry of Land, Infrastructure and Transport of Advanced Water Management Research Program (13AWMP-B066744-01).

Conflicts of Interest: The authors declare no conflict of interest. 


\section{References}

1. González-Rouco, J.F.; Jiménez, J.L.; Quesada, V.; Valero, F. Quality control and homogeneity of precipitation data in the southwest of Europe. J. Clim. 2001, 14, 964-978. [CrossRef]

2. Price, K.; Purucker, S.T.; Kraemer, S.R.; Babendreier, J.E.; Knightes, C.D. Comparison of radar and gauge precipitation data in watershed models across varying spatial and temporal scales. Hydrol. Process. 2014, 28, 3505-3520. [CrossRef]

3. Sikorska, A.; Seibert, J. Importance of precipitation data quality for streamflow predictions. Geophys. Res. Abstr. 2015, 17, 13369 .

4. Buarque, D.C.; De Paiva, R.C.D.; Clarke, R.T.; Mendes, C.A.B. A comparison of Amazon rainfall characteristics derived from TRMM, CMORPH and the Brazilian national rain gauge network. J. Geophys. Res. Atmos. 2011, 116. [CrossRef]

5. Kidd, C.; Bauer, P.; Turk, J.; Huffman, G.J.; Joyce, R.; Hsu, K.L.; Braithwaite, D. Intercomparison of high-resolution precipitation products over northwest Europe. J. Hydrometeorol. 2012, 13, 67-83. [CrossRef]

6. Thorndahl, S.; Einfalt, T.; Willems, P.; Nielsen, J.E.; Veldhuis, M.C.; Arnbjerg-Nielsen, K.; Rasmussen, M.R.; Molnar, P. Weather radar rainfall data in urban hydrology. Hydrol. Earth Syst. Sci. 2017, 21, 1359-1380. [CrossRef]

7. Westrick, K.J.; Mass, C.F.; Colle, B.A. The limitation of the WSR-88D radar network for quantitative precipitation measurement over the coastal western United States. Bull. Am. Meteorol. Soc. 1999, 80, 2289-2298. [CrossRef]

8. Rico-Ramirez, M.A.; Liguori, S.; Schellart, A.N.A. Quantifying radar-rainfall uncertainties in urban drainage flow modeling. J. Hydrol. 2015, 528, 17-28. [CrossRef]

9. Joyce, R.J.; Janowiak, J.E.; Arkin, P.A.; Xie, P. CMORPH: A method that produces global precipitation estimates from passive microwave and infrared data at high spatial and temporal resolution. J. Hydrometeorol. 2004, 5, 487-503. [CrossRef]

10. Kidd, C.; Huffman, G. Global precipitation measurement. Meteorol. Appl. 2011, 18, 334-353. [CrossRef]

11. Kidd, C.; Levizzani, V. Status of satellite precipitation retrievals. Hydrol. Earth Syst. Sci. 2011, 15, 1109-1116. [CrossRef]

12. Hou, A.Y.; Kakar, R.K.; Neeck, S.; Azarbarzin, A.A.; Kummerow, C.D.; Kojima, M.; Oki, R.; Nakamura, K.; Iguchi, T. The global precipitation measurement mission. Bull. Am. Meteorol. Soc. 2014, 95, 701-722. [CrossRef]

13. Su, F.; Hong, Y.; Lettenmaier, D.P. Evaluation of TRMM multisatellite precipitation analysis (TMPA) and its utility in hydrologic prediction in the La Plata basin. J. Hydrometeorol. 2008, 9, 622-639. [CrossRef]

14. Collischonn, B.; Collischonn, W.; Tucci, C.E.M. Daily hydrological modeling in the Amazon basin using TRMM rainfall estimates. J. Hydrol. 2008, 360, 207-216. [CrossRef]

15. Scheel, M.L.M.; Rohrer, M.; Huggel, C.; Villar, D.S.; Huffman, G.J. Evaluation of TRMM multi-satellite precipitation analysis (TMPA) performance in the Central Andes region and its dependency on spatial and temporal resolution. Hydrol. Earth Syst. Sci. 2011, 15, 2649-2663. [CrossRef]

16. Ouma, Y.O.; Owiti, T.; Kibiiy, J.; Ouma, Y.O.; Tateishi, R.; Kipkorir, E. Multitemporal comparative analysis of TRMM-3B42 satellite-estimated rainfall with surface gauge data at basin scales: Daily, decadal and monthly evaluations. Int. J. Remote Sens. 2012, 33, 7662-7684. [CrossRef]

17. Xue, X.; Hong, Y.; Limaye, A.S.; Gourley, J.J.; Huffman, G.J.; Khan, S.I.; Dorji, C.; Chen, S. Statistical and hydrological evaluation of TRMM-based multi-satellite precipitation analysis over the Wangchu Basin of Bhutan: Are the latest satellite precipitation products ready for use in ungauged basins? J. Hydrol. 2013, 499, 91-99. [CrossRef]

18. Stisen, S.; Sandholt, I. Evaluation of remote-sensing-based rainfall products through predictive capability in hydrological runoff modelling. Hydrol. Process. 2010, 24, 879-891. [CrossRef]

19. Behrangi, A.; Khakbaz, B.; Jaw, T.C.; AghaKouchak, A.; Hsu, K.; Sorooshian, S. Hydrologic evaluation of satellite precipitation products over a mid-size basin. J. Hydrol. 2011, 397, 225-237. [CrossRef]

20. Shen, Y.; Xiong, A.; Wang, Y.; Ha, P. Performance of high-resolution satellite precipitation products over China. J. Geophys. Res. Atmos. 2010, 115. [CrossRef]

21. Hirpa, F.A.; Gebremichael, M.; Hopson, T. Evaluation of high-resolution satellite precipitation products over very complex terrain in Ethiopia. J. Appl. Meteorol. Climatol. 2010, 49, 1044-1051. [CrossRef]

22. Meng, X.; Wang, H. Significance of the China meteorological assimilation driving datasets for the SWAT model (CMADS) of East Asia. Water (Switzerland) 2017, 9, 765. [CrossRef] 
23. Meng, X.Y.; Wang, H.; Lei, X.H.; Cai, S.Y.; Wu, H.J. Hydrological modeling in the Manas River Basin using Soil and Water Assessment Tool driven by CMADS. Teh. Vjesn. 2017, 24, 525-534.

24. Setegn, S.G.; Donoso, M.C. Sustanability of Intergrated Water Resources Management: Water Governace, Climate and Ecohydrology; Springer: Basel, Switzerland, 2015.

25. Bicknell, B.R.; Imhoff, J.C.; Kittle, J.L.; Donigian, A.S.; Johanson, R.C. Hydrologic Simulation Program-Fortran: User's Manual for Release 11; Environmental Research Laboratory, Office of Research and Development, U.S. Environmental Protection Agency: Athens, GA, USA, 1996.

26. Refsgaard, J.C.; Storm, B. MIKE SHE. In Computer Models of Watershed Hydrology; Sing, V.P., Ed.; Water Resource Publications: Highland Ranch, CO, USA, 1995; pp. 806-846.

27. USACE. HEC-5 Simulation of Flood Control and Conservation System; US Army Corps of Engineers, Hydrologic Engineering Center: Davis, CA, USA, 1998.

28. Arnold, J.G.; Srinivasan, R.; Muttiah, R.S.; Williams, J.R. Large area hydrologic modeling and assessment part I: Model development. J. Am. Water Resour. Assoc. 1998, 34, 73-89. [CrossRef]

29. Sivapalan, M.; Takeuchi, K.; Franks, S.W.; Gupta, V.K.; Karambiri, H.; Lakashmi, V.; Liang, X.; McDonnell, J.J.; Mendiondo, E.M.; O'connell, P.E.; et al. IAHS Decade on Predictions in Ungauged Basins (PUB), 2003-2012: Shaping an exciting future for the hydrological sciences. Hydrol. Sci. J. 2003, 48, 857-880. [CrossRef]

30. Eckhardt, K.; Arnold, J.G. Automatic calibration of a distributed catchment model. J. Hydrol. 2001, 251, 103-109. [CrossRef]

31. Arnold, J.G.; Allen, P.M. Automated methods for estimating baseflow and ground water recharge from streamflow records. J. Am. Water Resour. Assoc. 1999, 35, 411-424. [CrossRef]

32. White, K.L.; Chaubey, I. Sensitivity analysis, calibration, and validations for a multisite and multivariable SWAT model. J. Am. Water Resour. Assoc. 2005, 41, 1077-1089. [CrossRef]

33. Kang, M.S.; Park, S.W.; Lee, J.J.; Yoo, K.H. Applying SWAT for TMDL programs to a small watershed containing rice paddy fields. Agric. Water Manag. 2006, 79, 72-92. [CrossRef]

34. Kim, N.W.; Chung, I.M.; Won, Y.S.; Arnold, J.G. Development and application of the integrated SWAT-MODFLOW model. J. Hydrol. 2008, 356, 1-16. [CrossRef]

35. Bae, D.H.; Jung, I.W.; Lettenmaier, D.P. Hydrologic uncertainties in climate change from IPCC AR4 GCM simulations of the Chungju Basin, Korea. J. Hydrol. 2011, 401, 90-105. [CrossRef]

36. Kim, N.W.; Lee, J.E.; Kim, J.T. Assessment of flow regulation effects by dams in the Han River, Korea, on the downstream flow regimes using SWAT. J. Water Resour. Plan. Manag. 2012, 131, 24-35. [CrossRef]

37. Shope, C.L.; Maharjan, G.R.; Tenhunen, J.; Seo, B.; Kim, K.; Riley, J.; Arnhold, S.; Koellner, T.; Ok, Y.S.; Peiffer, S.; et al. Using the SWAT model to improve process descriptions and define hydrologic partitioning in South Korea. Hydrol. Earth Syst. Sci. 2014, 18, 539-557. [CrossRef]

38. Cho, K.H.; Pachepsky, Y.A.; Kim, M.; Pyo, J.; Park, M.H.; Kim, Y.M.; Kim, J.W.; Kim, J.H. Modeling seasonal variability of fecal coliform in natural surface waters using the modified SWAT. J. Hydrol. 2016, 535, 377-385. [CrossRef]

39. Kim, J.P.; Jung, I.; Park, K.W.; Yoon, S.K.; Lee, D. Hydrological utility and uncertainty of multi-satellite precipitation products in the mountainous region of South Korea. Remote Sens. 2016, 8, 608. [CrossRef]

40. Smith, P.J.; Panziera, L.; Beven, K.J. Forecasting flash floods using data-based mechanistic models and NORA radar rainfall forecasts. Hydrol. Sci. J. 2014, 59, 1343-1357. [CrossRef]

41. KOWACO. The Pre-Investigation Report for Groundwater Resources; Korea Water Resources Corporation: Daejeon, Korea, 1993; p. 340.

42. Korea Meteorological Administration. Annual Report 2016; Korea Meteorological Administration: Seoul, Korea, 2016; p. 49.

43. Kim, J.S.; Jain, S.; Yoon, S.K. Warm season streamflow variability in the Korean Han River Basin: Links with atmospheric teleconnections. Int. J. Climatol. 2012, 32, 635-640. [CrossRef]

44. Lee, K.S.; Bong, Y.S.; Lee, D.; Kim, Y.; Kim, K. Tracing the sources of nitrate in the Han River watershed in Korea, using $\delta^{15} \mathrm{~N}_{-N_{3}}$ and $\delta^{18} \mathrm{O}-\mathrm{NO}_{3}$ values. Sci. Total Environ. 2008, 395, 117-124. [CrossRef] [PubMed]

45. Heo, B.-H.; Kim, K.-E.; Kang, S.-G. Removals of noises from automatic weather station data and radial velocity data of doppler weather radar using modified median filter. J. Korean Meteorol. Soc. 1999, 35, 127-135.

46. Li, D.; Christakos, G.; Ding, X.; Wu, J. Adequacy of TRMM satellite rainfall data in driving the SWAT modeling of Tiaoxi catchment (Taihu lake basin, China). J. Hydrol. 2018, 556, 1139-1152. [CrossRef] 
47. Huffman, G.J.; Adler, R.F.; Bolvin, D.T.; Gu, G.; Nelkin, E.J.; Bowman, K.P.; Hong, Y.; Stocker, E.F.; Wolff, D.B. The TRMM multi-satellite precipitation analysis (TMPA): Quasi-global, multi-year, combined-sensor precipitation estimates at fine scale. J. Hydrometeorol. 2007, 8, 38-55. [CrossRef]

48. Sorooshian, S.; Hsu, K.L.; Gao, X.; Gupta, H.V.; Imam, B.; Braithwaite, D. Evaluation of PERSIANN system satellite-based estimates of tropical rainfall. Bull. Am. Meteorol. Soc. 2000, 81, 2035-2046. [CrossRef]

49. Ashouri, H.; Hsu, K.L.; Sorooshian, S.; Braithwaite, D.K.; Knapp, K.R.; Cecil, L.D.; Nelson, B.R.; Prat, O.P. PERSIANN-CDR: Daily precipitation climate data record from multisatellite observations for hydrological and climate studies. Bull. Am. Meteorol. Soc. 2015, 96, 69-83. [CrossRef]

50. Neitsch, S.L.; Arnold, J.G.; Kiniry, J.R.; Williams, J.R. Soil and Water Assessment Tool Theoretical Documentation Version 2009; Texas Water Resources Institute: College Station, TX, USA, 2011.

51. Abbaspour, K.C.; Johnson, C.A.; van Genuchten, M.T. Estimating uncertain flow and transport parameters using a sequential uncertainty fitting procedure. Vadose Zone J. 2004, 3, 1340-1352. [CrossRef]

52. Yang, J.; Reichert, P.; Abbaspour, K.C.; Xia, J.; Yang, H. Comparing uncertainty analysis techniques for a SWAT application to the Chaohe Basin in China. J. Hydrol. 2008, 358, 1-23. [CrossRef]

53. Narsimlu, B.; Gosain, A.K.; Chahar, B.R.; Singh, S.K.; Srivastava, P.K. SWAT model calibration and uncertainty analysis for streamflow prediction in the Kunwari River Basin, India, using sequential uncertainty fitting. Environ. Process. 2015, 2, 79-95. [CrossRef]

54. Wu, H.; Chen, B. Evaluating uncertainty estimates in distributed hydrological modeling for the Wenjing River watershed in China by GLUE, SUFI-2, and ParaSol methods. Ecol. Eng. 2015, 76, 110-121. [CrossRef]

55. Khoi, D.N.; Thom, V.T. Parameter uncertainty analysis for simulating streamflow in a river catchment of Vietnam. Glob. Ecol. Conserv. 2015, 4, 538-548. [CrossRef]

56. Willmott, C.J.; Matsuura, K. Advantages of the mean absolute error (MAE) over the root mean square error (RMSE) in assessing average model performance. Clim. Res. 2005, 30, 79-82. [CrossRef]

57. Baik, J.; Choi, M. Spatio-temporal variability of remotetely sensed precipitation data from COMS and TRMM: Case study of Korean peninsula in East Asia. Adv. Space Res. 2015, 56, 125-1138. [CrossRef]

58. Moriasi, D.N.; Arnold, J.G.; Van Liew, M.W.; Bingner, R.L.; Harmel, R.D.; Veith, T.L. Model evaluation guidelines for systematic quantification of accuracy in watershed simulations. Trans. ASABE 2007, 50, 885-900. [CrossRef]

59. Dai, A. Precipitation characteristics in eighteen coupled climate models. J. Clim. 2006, 19, 4605-4630. [CrossRef]

60. Dinku, T.; Chidzambwa, S.; Ceccato, P.; Connor, S.J.; Ropelewski, C.F. Validation of high-resolution satellite rainfall products over complex terrain. Int. J. Remote Sens. 2008, 29, 4097-4110. [CrossRef]

61. Ma, L.; Ascough Ii, J.C.; Ahuja, L.R.; Shaffer, M.J.; Hanson, J.D.; Rojas, K.W. Root Zone Water Quality Model sensitivity analysis using Monte Carlo simulation. Trans. ASAE 2000, 43, 883-895. [CrossRef]

62. Hromadka, T.V.; McCuen, R.H. Uncertainty estimates for surface runoff models. Adv. Water Resour. 1998, 11, 2-14. [CrossRef]

63. Maskey, S.; Guinot, V.; Price, R.K. Treatment of precipitation in rainfall-runoff modelling: A fuzzy set approach. Adv. Water Resour. 2004, 27, 889-898. [CrossRef]

64. Jones, P.D.; Lister, D.H.; Wilby, R.L.; Kostopoulou, E. Extended riverflow reconstructions for England and Wales, 1865-2002. Int. J. Climatol. 2006, 25, 219-231. [CrossRef]

65. Andreassian, V.; Perrin, C.; Michel, C.; Usart-Sanchez, I.; Lavabre, J. Impact of imperfect rainfall knowledge on the efficency and the parameters of watershed models. J. Hydrol. 2001, 250, 206-223. [CrossRef]

66. Gebregiorgis, A.S.; Hossain, F. Understanding the dependence of satellite rainfall uncertainty on topography and climate for hydrologic model simulation. IEEE Trans. Geosci. Remote Sens. 2013, 51, 704-718. [CrossRef]

67. Xu, S.G.; Niu, Z.; Shen, Y. Understanding the dependence of the uncertainty in a satellite precipitation data set on the underlying surface and a correction method based on geogrphically weighted reggression. Int. J. Remote Sens. 2014, 35, 6508-6521. [CrossRef]

68. Bitew, M.M.; Gebremichael, M. Assessment of satellite rainfall products for streamflow simulation in medium watersheds of the Ethiopian highlands. Hydrol. Earth Syst. Sci. 2011, 15, 1147-1155. [CrossRef]

69. Artan, G.; Gadain, H.; Smith, J.L.; Asante, K.; Bandaragoda, C.J.; Verdin, J.P. Adequacy of satellite derived rainfall data for streamflow modeling. Nat. Hazards 2007, 43, 167-185. [CrossRef]

(C) 2018 by the authors. Licensee MDPI, Basel, Switzerland. This article is an open access article distributed under the terms and conditions of the Creative Commons Attribution (CC BY) license (http:/ / creativecommons.org/licenses/by/4.0/). 